\title{
CRECIMIENTO ECONÓMICO EN CHILE: EVIDENCIA, FUENTES Y PERSPECTIVAS*
}

\author{
José De Gregorio
}

\begin{abstract}
Este artículo revisa la experiencia chilena de crecimiento, con especial énfasis en el rápido crecimiento que comenzó a mediados de los años ochenta, cuando la economía se recuperaba de la crisis de 1982, para moderarse a fines de los noventa. También se analiza y se descompone la evidencia sobre el crecimiento y la actividad, revisando las fortalezas y debilidades tras el despegue económico de Chile y los elementos que sustentan el crecimiento futuro. Por último, se presentan estimaciones de la tasa de crecimiento potencial de largo plazo para la economía chilena.
\end{abstract}

José De Gregorio. Doctor en Economía del Massachusetts Institute of Technology (MIT). Vicepresidente del Banco Central de Chile. Profesor Titular de la Universidad de Chile. Fue Ministro de Economía, Minería y Energía.

* Se agradecen los comentarios y sugerencias de César Calderón, Sebastián Edwards, Rodrigo Fuentes, Joe Ramos, Rodrigo Valdés y Rodrigo Vergara. Agradezco también a Gonzalo Becerra, y especialmente a Marco Núñez por su excelente ayuda en la investigación y en la recopilación de los datos. Todas las opiniones expresadas en este artículo son mías. E-mail: jdegrego@bcentral.cl. 


\section{Introducción}

$\mathrm{L}$

as tasas de crecimiento observadas para la economía chilena desde la segunda mitad de los 80 han sido altas, no solo según los estándares históricos propios de Chile, sino también desde una perspectiva comparativa internacional. ¿Cuáles han sido las causas de este despegue? ¿Qué promete para el futuro este récord de crecimiento actual? ¿Cuáles fueron los factores subyacentes claves en el éxito de Chile y cuáles son las debilidades que se mantienen? Estas preguntas son relevantes no sólo para los formuladores de políticas y otras personas interesadas en Chile, sino también para poder recoger las lecciones más generales para otros países. El propósito de este trabajo es explorar estos temas.

El trabajo comienza con un repaso de la historia del crecimiento en Chile a partir del siglo XIX, para realizar luego un análisis de contabilidad del crecimiento para las épocas recientes. Para resumir, la economía chilena sufrió de un crecimiento lento hasta la mitad de los años 80. Posteriormente gozó de una recuperación sólida tras la crisis de la deuda, y este crecimiento siguió durante la mayor parte de los 90. Después de 1998, el crecimiento se tornó más lento, pero se mantuvo dentro de su tasa media para el siglo XX como un todo, y de hecho por sobre la tasa de los primeros 85 años del siglo.

En las próximas dos secciones, este artículo examina las fortalezas y las debilidades de la economía chilena. Una posibilidad habría sido la estimación de regresiones para el crecimiento en un conjunto amplio de países y un examen de cómo Chile se comportó con los diferentes factores que tal análisis destaca como determinantes del crecimiento de largo plazo ${ }^{1}$. Una desventaja de esta estrategia, sin embargo, es que se limita a un conjunto específico de variables explicativas. La inclusión de variables adicionales reduce los grados de libertad, hay colinealidad entre los regresores, y los modelos teóricos no explican correctamente la inclusión simultánea de todas las variables. Por estos motivos, opto por una estrategia más ecléctica, que considera aquellos determinantes de crecimiento que se han demostrado relevantes en muchas otras comparaciones entre diferentes países. Por supuesto, esta estrategia está acotada a mi propia lectura de la abundante literatura empírica sobre los determinantes del crecimiento y su relevancia para Chile.

Entre las fortalezas chilenas identifico y examino el rol de la inflación baja, la disciplina fiscal, la apertura a la economía mundial, un sistema financiero sólido, la fortaleza institucional y una buena infraestructura. Chile está

\footnotetext{
${ }^{1}$ Esto se hizo en un interesante estudio de Gallego y Loayza (2002).
} 
entre los primeros en cuanto a la eficiencia de su regulación de las instituciones relevantes para los negocios y otras actividades, pero también aparecen algunas debilidades, principalmente relacionadas con los costos de los procesos de quiebra de empresas. Entre las debilidades enfatizo el rol de la desigualdad de los ingresos, aunque las políticas chilenas han podido minimizar los efectos distorsionadores que tal desigualdad tiende a introducir en la formulación de políticas. También examino las debilidades en la investigación y el desarrollo en Chile (en cuanto a su nivel y composición), la calidad de la educación, el clima económico regional y su fracaso en la promoción del intercambio.

Luego, presento la evidencia de una serie de estudios sobre las perspectivas de largo plazo para la economía chilena. Una tasa de crecimiento PIB de 5 por ciento al año parece ser una estimación razonable para el futuro. Se podría lograr una mayor tasa de crecimiento, pero requeriría superar algunas de las debilidades del ambiente actual de crecimiento recién mencionadas. En la última sección de este artículo se presentan las conclusiones.

\section{Evidencia histórica, de contabilidad de crecimiento y comparaciones internacionales}

El crecimiento económico rápido es un fenómeno relativamente nuevo para Chile. Antes de que el crecimiento despegara a mediados de los 80 , Chile había experimentado algunos períodos transitorios de crecimiento rápido, pero la tasa de crecimiento en aquellos episodios fue bastante menor que las experimentadas por el país más recientemente y no muy diferente de la tasa contemporánea de crecimiento de la economía mundial en su conjunto.

Esta sección presenta los datos de varias fuentes. La intención no es entregar cifras precisas y definitivas, sino revelar tendencias generales, que deberían ser las mismas independientemente de los datos utilizados. Para las comparaciones nacionales se usan las cuentas nacionales oficiales del Banco Central de Chile y datos históricos de Díaz et al. (2003). Para las comparaciones internacionales a largo plazo se ocupan Maddison (1995), y para los datos comparativos más recientes entre diferentes países utilizaré los Penn World Tables (versión 6.1.).

\subsection{Una perspectiva de largo plazo}

El Gráfico $N^{\circ} 1$ examina la historia del producto nacional de Chile desde la independencia, con los datos recolectados por Díaz et al. (2004). El 
GRÁFICO N 1: $\quad$ PIB PER CÁPITA 1810-2003 (1900=100)

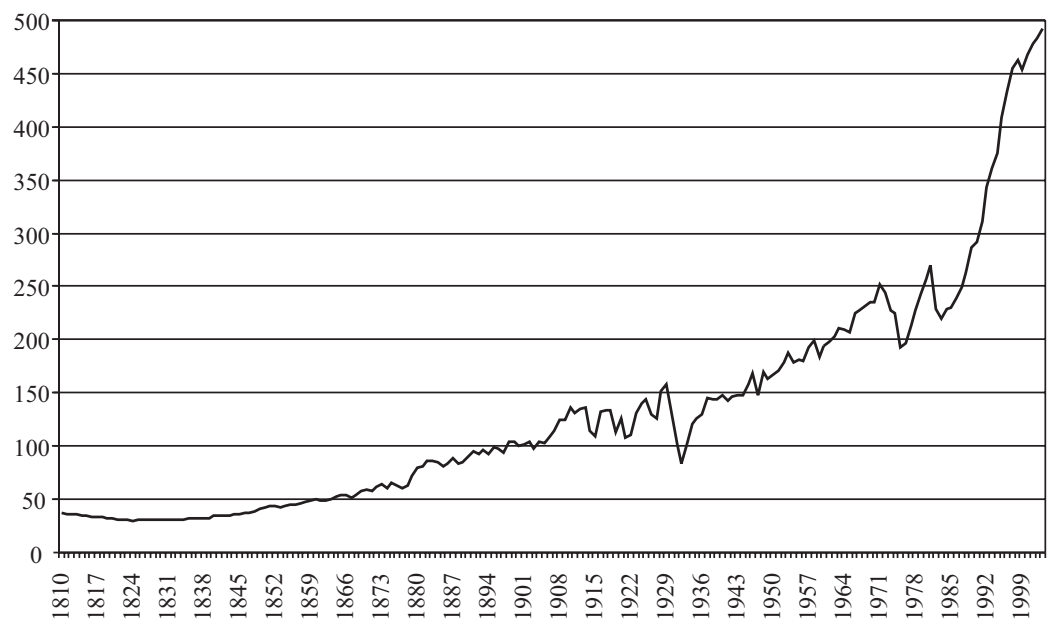

Cuadro $\mathrm{N}^{\mathrm{0}} 1$ resume las tasas medias de crecimiento del PIB y del PIB per cápita durante períodos seleccionados, cuyos puntos finales marcan cambios en el crecimiento de tendencia.

Desde la Independencia hasta la Guerra del Pacífico, el crecimiento por habitante fue lento, sólo 0,8 por ciento anual. Desde entonces y hasta la Depresión, la economía creció un poco más rápido, en 1,5 por ciento al año

CUADRO No 1 : $\quad$ PIB Y PIB POR HABITANTE, 1810-2003

Per cápita Total

$\begin{array}{lcc}1811-1878 & 0,8 & 2,7 \\ 1879-1929 & 1,5 & 2,6 \\ 1930-1950 & 0,3^{*} & 2,1 \\ 1950-1971 & 2,0 & 4,2 \\ 1972-1983 & -1,1 & 0,4 \\ 1984-1997 & 5,3 & 7,1 \\ 1998-2003 & 1,3 & 2,6 \\ 1900-1999 & 1,5 & 3,2 \\ 1900-1984 & 0,9 & 4,1 \\ 1985-2003 & 4,1 & 5,7\end{array}$

* La tasa de crecimiento del PIB por habitante entre 1932 y 1950 fue de 3,9\%.

Fuente: Díaz et al. (2004) y Banco Central de Chile. 
en términos per cápita, pero con importantes fluctuaciones que reflejaban principalmente la crisis del salitre de 1910. El PIB por habitante de Chile cayó precipitadamente en 45 por ciento durante los años de la Depresión 1930-1932, pero se recuperó vigorosamente después y continuó con un crecimiento moderado (de 2,6 por ciento anual en promedio) hasta 1971. Desde 1972 hasta 1983, el PIB por habitante cayó. Esta etapa comenzó con un descenso en el producto entre 1972 y 1975 que culminó en la crisis de la deuda y una caída adicional del producto en 1982-1983. Luego se inició un período de crecimiento rápido, que se prolongó hasta fines de los 90 . Una forma de resumir las tendencias en el crecimiento de Chile durante el siglo XX es decir que, tomando como punto de partida 1900, el PIB de Chile demoró 62 años en duplicarse, pero desde entonces requirió solo 30 años para duplicarse nuevamente.

La elección del año en el cual el crecimiento chileno realmente despegó es necesariamente arbitraria, en particular porque los años que siguieron inmediatamente a la recesión de 1982, cuando el producto cayó en un 13,5 por ciento, en esencia reflejaron una recuperación. Tomando en cuenta esta precaución, de modo de ofrecer una simple ilustración, se puede dividir el siglo en dos períodos, antes y después de 1985. Mientras desde 1900 hasta 1985 el PIB por habitante creció en una modesta tasa anual de 0,9 por ciento, la tasa media de crecimiento anual para todo el siglo fue 1,5 por ciento, gracias a una fuerte alza en la tasa de crecimiento después de $1985^{2}$.

El crecimiento se desaceleró nuevamente durante 1998, donde las repercusiones de la crisis asiática y una fuerte crisis de liquidez nacional produjeron una caída en el producto de 0,8 por ciento en 1999. Desde entonces el crecimiento fue más lento. Por esto mismo, a veces se identifica al período 1985-1997 como la “época dorada” de Chile, durante el cual el crecimiento promedió un 7,1 por ciento anual y el ingreso por habitante se duplicó. Desde entonces, hasta el año 2003, el crecimiento del PIB por habitante ha promediado 1,3 por ciento anual, una fracción de la tasa de los 13 años previos, pero de todas maneras fue mayor al promedio registrado durante los 85 primeros años del siglo XX.

Incluso el período posterior a 1985 se podría dividir en dos: la época dorada, que duró hasta 1997 y, en adelante, la de un crecimiento más lento. Esto ha causado preocupación por la verdadera capacidad de crecimiento

${ }^{2}$ Según Maddison (1995), la fuente que se utiliza aquí para las comparaciones internacionales, la tasa media de crecimiento del PIB per cápita durante los primeros 85 años del siglo fue 1,2 por ciento. Al completar esto con las series de datos oficiales se llega a una tasa de crecimiento de 1,7 por ciento para el siglo XX en su conjunto. Esto es algo mayor que los datos de Díaz et al. (2004) mencionados en el texto, pero no produce una diferencia significativa en la interpretación. 
de Chile: ¿la época dorada fue sólo un fenómeno pasajero o, Chile puede retomar ese nivel de crecimiento? Una señal de esperanza es que, en la medida que la economía se ha ido recuperando de la recesión de 1999, ha vuelto a tasas de crecimiento de entre 2 y 5 por ciento.

El Cuadro $\mathrm{N}^{\circ} 2$ ofrece una visión histórica del crecimiento de Chile desde una perspectiva internacional. Los datos son de Maddison (1995), que es la fuente más comprensiva y completa de datos de largo plazo para comparaciones históricas y entre países, aunque los datos para la mayoría de los países están disponibles sólo hasta 1992. Entre los países de este cuadro, Chile muestra una de las tasas de crecimiento más bajas para todo el siglo: su PIB per cápita aumentó casi cuatro veces. En América Latina, sólo Argentina, una de las grandes desilusiones de la economía mundial, creció a una tasa menor. En 1900, tanto Argentina como Chile gozaban de un ingreso mayor al de Finlandia y Noruega, pero ya en 1950, Noruega había sobrepasado a Chile y Finlandia lo hizo desde 1960. En América Latina, el crecimiento de Brasil partió con mucha fuerza en la segunda mitad del siglo, pero se detuvo abruptamente después de 1980.

CUADRO N 2: $\quad$ PIB PER CÁPITA 1900-1992 (PPC, DÓLARES DE 1990)

\begin{tabular}{lrrrrrrr}
\hline & 1900 & 1913 & 1950 & 1960 & 1970 & 1992 & $\frac{1992}{1900}$ \\
& & & & & & & \\
& & & & & & & \\
Chile & & & & & & & \\
Alemania & 1.949 & 2.653 & 3.827 & 4.304 & 5.217 & 7.238 & 3,71 \\
Argentina & 3.134 & 3.833 & 4.281 & 8.463 & 13.152 & 19.351 & 6,17 \\
Australia & 2.756 & 3.797 & 4.987 & 5.559 & 7.970 & 7.616 & 2,76 \\
Brasil & 4.299 & 5.505 & 7.218 & 8.539 & 11.637 & 16.237 & 3,78 \\
China & 704 & 839 & 1.673 & 2.335 & 3.913 & 4.637 & 6,59 \\
Finlandia & 652 & 688 & 614 & 878 & 1.186 & 3.098 & 4,75 \\
Irlanda & 1.620 & 2.050 & 4.131 & 6.051 & 9.302 & 14.646 & 9,04 \\
Japón & 2.495 & 2.733 & 3.518 & 4.368 & 6.250 & 11.711 & 4,69 \\
Corea & 1.135 & 1.334 & 1.873 & 3.879 & 9.448 & 19.425 & 17,11 \\
México & 850 & 948 & 876 & 1.302 & 2.208 & 10.010 & 11,78 \\
Nueva Zelanda & 1.157 & 1.467 & 2.085 & 2.781 & 4.189 & 5.112 & 4,42 \\
Noruega & 4.320 & 5.178 & 8.495 & 9.491 & 11.278 & 13.947 & 3,23 \\
Filipinas & 1.762 & 2.275 & 4.969 & 6.549 & 9.122 & 17.543 & 9,96 \\
España & 1.033 & 1.418 & 1.293 & 1.488 & 1.766 & 2.213 & 2,14 \\
EE.UU. & 2.040 & 2.255 & 2.397 & 3.437 & 7.291 & 12.498 & 6,13 \\
& 4.096 & 5.307 & 9.573 & 11.193 & 14.854 & 21.558 & 5,26 \\
Chile/EE.UU. (\%) & & & & & & & \\
Chile/Europa Occidental (\%) & 65,1 & 77,4 & 68,3 & 53,3 & 41,0 & 41,3 & \\
& & & & & & &
\end{tabular}

Fuente: Maddison (1995). 
El pobre desempeño de Chile después de 1913, coincidente con el colapso del salitre, derivó en una brecha que se amplió persistentemente en el ingreso per cápita de Chile comparado con el de EE.UU. y Europa Occidental. El ingreso por habitante de Chile cayó desde la mitad del de EE.UU. en 1913 a 35 por ciento en 1970, tocando piso en 1975. Desde entonces, esta brecha se ha ido cerrando, más sistemáticamente desde mediados de los 80 , llegando a 39 por ciento del nivel de EE.UU. en 2000.

\subsection{Crecimiento e inversión desde los años 60}

El Cuadro $\mathrm{N}^{\circ}$ 3, que ocupa los datos de Penn World Tables (versión 6.1) desde 1960, ofrece una comparación internacional más reciente. Durante los años 60, Chile y América Latina en su conjunto lograron una tasa razonable de crecimiento de 2,2 por ciento anual, que estaba por debajo del promedio mundial y del de EE.UU., y menor a lo que se consideraría un buen rendimiento. En este período, la variabilidad del crecimiento de la región era baja, y la mayoría de los países latinoamericanos experimentaron tasas de crecimiento positivas. Por este motivo, se recuerda a los 60 como una buena época para la región. Sin embargo, como demuestra el cuadro, fue un período aún mejor para el resto del mundo en su conjunto, y, por lo tanto, la brecha de ingreso entre América Latina y el mundo desarrollado aumentó.

CUADRO No 3: $\quad$ PIB PER CÁPITA. CRECIMIENTO DESDE 1960

\begin{tabular}{lrrrrc}
\hline & $60 s$ & $70 s$ & $80 s$ & $90 s$ & $1960-2000$ \\
\hline Chile & & & & & \\
América Latina (1) & 2,2 & 1,2 & 1,3 & 4,8 & 2,4 \\
Asia Oriental (2) & 2,2 & 2,5 & $-0,9$ & 1,8 & 1,4 \\
Japón & 4,7 & 5,4 & 4,5 & 4,0 & 4,6 \\
EE.UU. & 9,3 & 3,1 & 3,5 & 1,1 & 4,2 \\
Mundo (3) & 2,9 & 2,7 & 2,2 & 2,3 & 2,5 \\
& 2,5 & 2,0 & 1,0 & 1,3 & 1,7 \\
\hline
\end{tabular}

(1) Los 15 países con el PIB más alto: Argentina, Bolivia, Brasil, Chile, Colombia, Costa Rica, República Dominicana, Ecuador, El Salvador, Guatemala, México, Paraguay, Perú, Uruguay y Venezuela.

(2) China, Hong Kong, Indonesia, Corea del Sur, Malasia, Filipinas, Singapur, Taiwán y Tailandia.

(3) 85 países para los cuales existen datos, promedios no ponderados.

Fuente: De Gregorio y Lee (2004), basado en Aten, Heston y Summers (2002). 
De particular importancia para Chile fueron los precios del cobre, que en los 60 llegaron a su punto más alto de la postguerra hasta hoy.

Un patrón similar se observa para América Latina en los 70, pero el rendimiento de Chile quedó muy por debajo del resto de la región y del mundo en su conjunto. Esto se debe no solo al shock del petróleo, sino también a las políticas nacionales aplicadas durante dicha década, comenzando por la experiencia populista de principios de los 70, y seguida por la brusca caída en el producto durante la estabilización basada en una fuerte contracción monetaria a mediados de los 70 junto al primer shock del petróleo. Es interesante destacar que, aunque el shock del petróleo sin duda redujo el crecimiento mundial, América Latina creció más rápidamente que en la década precedente, principalmente Brasil ${ }^{3}$, cuyo crecimiento por habitante, ajustado por su paridad de poder de compra (PPC), creció a una tasa anual de 5,7 por ciento. Esto sugiere que el descenso en el crecimiento de Chile se debía mucho más a factores domésticos.

En contraste, aunque los años 80 fueron una "década perdida" para América Latina, lo fue menos para Chile, que ya comenzaba a cosechar los beneficios de las reformas favorables al crecimiento. En efecto, a pesar del profundo descenso en el producto durante el colapso de 1982, la economía se repuso rápidamente, y durante la década su crecimiento promedió 2,2 puntos porcentuales por encima del promedio de los 15 mayores países de la región. Al comparar los patrones de colapso y recuperación durante la crisis de América Latina y la crisis posterior del Este de Asia, De Gregorio y Lee (2004) observan que Chile, y México después del “Tequilazo”, son los únicos países de América Latina cuyas trayectorias de crecimiento siguieron el patrón en forma de $\mathrm{V}$ que caracterizó a los países asiáticos, o sea, experimentaron una profunda caída seguida por una fuerte recuperación. El Cuadro $\mathrm{N}^{\circ} 3$ muestra claramente que el crecimiento rápido de Chile fue un fenómeno de los 90, aunque comenzó a mediados de los 80. La economía chilena pudo lograr una tasa récord de crecimiento no sólo para sus propios estándares históricos sino también al compararla con las internacionales, más que triplicando la tasa media (sin ponderar) de crecimiento del mundo en su conjunto.

El Gráfico $\mathrm{N}^{\circ} 2$ destaca todavía más el buen rendimiento de la economía chilena a fines de los 80 y durante los 90, y la desaceleración a fines de la década de los 90. América Latina no muestra ningún aumento en el ingreso desde la crisis asiática de fines de los 90 . El crecimiento para el conjunto de los mercados emergentes también descendió durante la crisis asiática, pero después se recuperó. En Chile la desaceleración comenzó en 1998 y

${ }^{3}$ De todas maneras, los promedios del Cuadro № 3 no están ponderados. 
GRÁFICO N 2: $\quad$ PIB PER CÁPITA 1980-2003 (1980=100)*

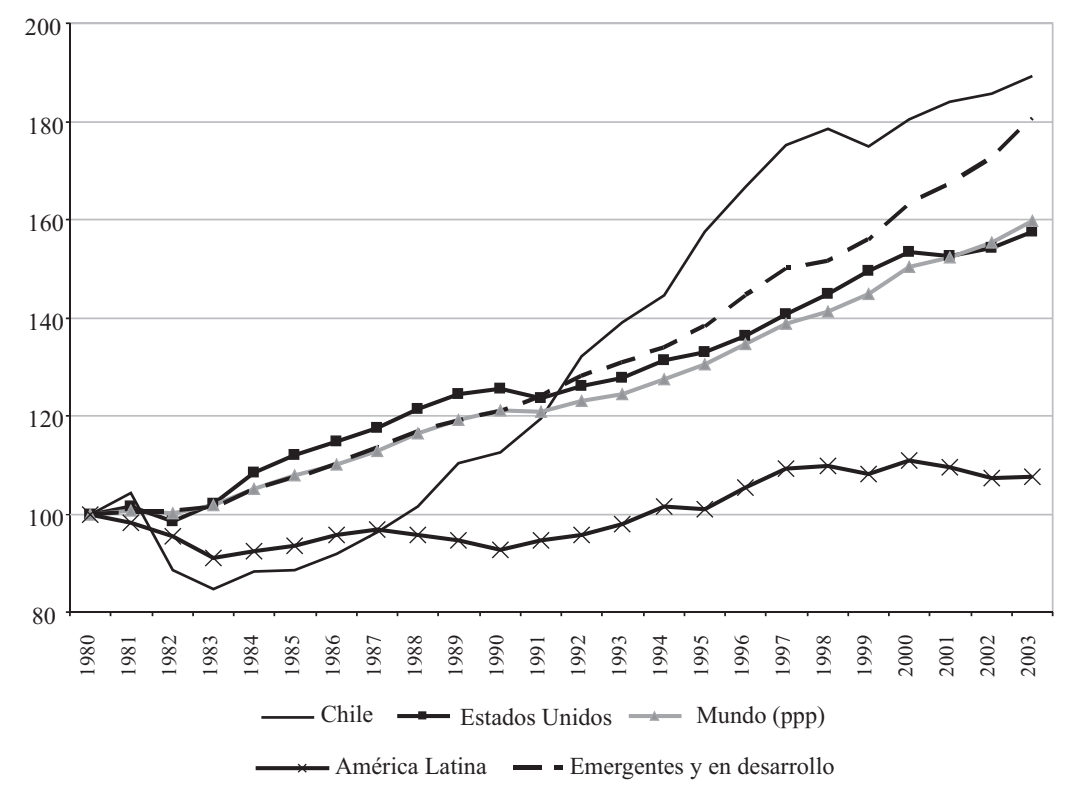

* El gráfico está basado en los datos del World Economic Outlook del Fondo Monetario Internacional, y los promedios por grupos de países están calculados utilizando sus pesos relativos de PPC.

Fuente: IMF: World Economic Outlook, y Banco Central de Chile.

siguió con la recesión de 1999. Desde entonces, el tema de cómo volver a experimentar una tasa de crecimiento más cercana a la de la época dorada ha sido uno de los temas más importantes en las discusiones de política en Chile. Sin embargo, desde una perspectiva de más largo aliento sobre la economía chilena permite concluir que, incluso, este período de crecimiento lento ha sido bueno en términos históricos. Entre 1998 y 2003, la tasa de crecimiento del PIB per cápita promedió 1,3 por ciento anual, comparado con el 1,2 por ciento anual entre 1900 y 1985 . Durante este período de menor crecimiento, Chile lo hizo por debajo del promedio mundial de 2,4 por ciento anual, y más lentamente que EE.UU., con crecimiento de 1,9 por ciento anual. Pero con la recuperación que se espera para 2004-2005, la tasa de crecimiento del PIB per cápita debería aumentar a 2 por ciento al año, aproximadamente.

Como señala el Gráfico $\mathrm{N}^{\circ}$ 3, la inversión en Chile llegó a su punto máximo durante el despegue de los 90. Como veré más adelante, el aporte de capital al crecimiento fue clave. Sin embargo, no analizaré la fortaleza o 
GRÁFICO No 3: $\quad$ TASA DE INVERSIÓN, 1960-2003

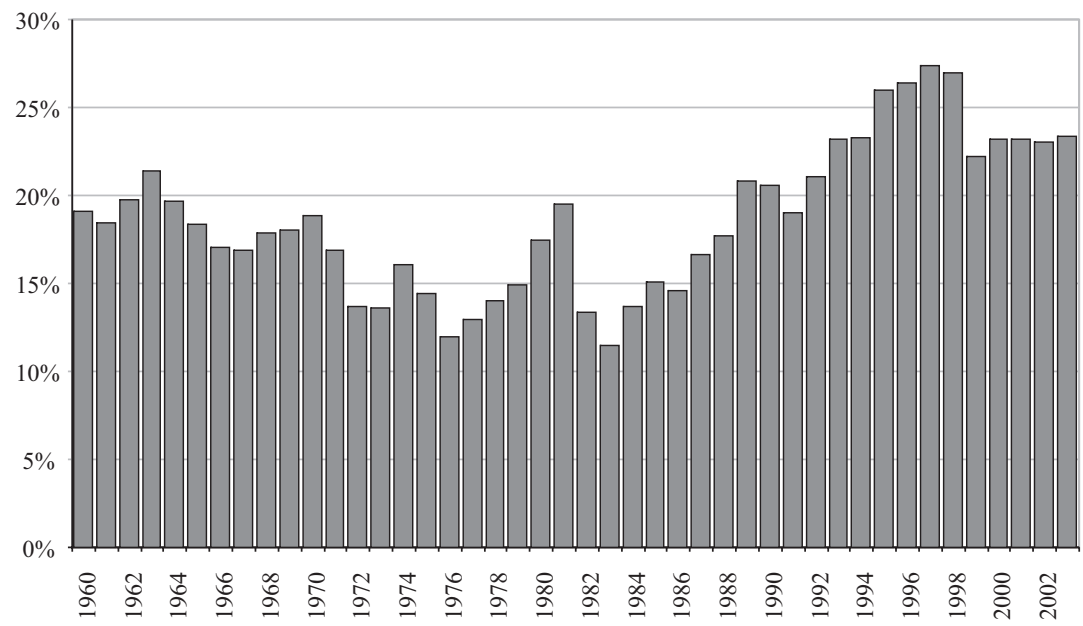

Fuente: Banco Central de Chile: Indicadores Económicos y Sociales de Chile 1960-2000 y Cuentas Nacionales.

debilidad de la inversión en el crecimiento de Chile por dos motivos. Primero, sabemos que el crecimiento es el resultado de la acumulación de factores (uno de los cuales es el capital físico) y la mayor productividad. Además los factores que favorecen el crecimiento son también los que elevan la inversión y la productividad. Por ejemplo, el hecho de ser una economía abierta aporta a ambas: a la productividad y a la inversión. Más aún, en el típico modelo neoclásico de crecimiento (Solow), es la productividad la que impulsa el crecimiento y la inversión. En otras palabras, la inversión es endógena.

En segundo lugar, una inversión mayor podría resultar de factores que no afectan la productividad. O sea, podría haber políticas económicas que afecten sólo a la inversión, y así aumentar el crecimiento a través de la acumulación de capital solamente. No obstante, esta cuestión ha sido resuelta en la literatura empírica. Según la mayoría de las estimaciones, al incluir la tasa de inversión separadamente de los otros factores determinantes para el crecimiento en las regresiones entre países, se obtiene un coeficiente para la tasa de inversión de aproximadamente 0,07 , que implica que, incluso un alza relativamente grande en la razón inversión-PIB, de unos cinco puntos porcentuales, podría aumentar la tasa de crecimiento en sólo 0,35 puntos porcentuales. Por este motivo, excluyo la inversión como factor fundamental que induce al crecimiento, sino que la considero el resultado 
de un escenario favorable al crecimiento. Ésta ha sido la misma ruta seguida por otros estudios del despegue del crecimiento en Chile, que utilizan metodologías diferentes (Bergoeing et al., 2002; Gallego y Loayza, 2002).

No obstante, es posible imaginar políticas que afectarían el crecimiento principal o incluso exclusivamente a través de la inversión. Las políticas tributarias constituyen un ejemplo importante, y debates recientes en Chile se han enfocado en el rol de la tributación corporativa. Según la evidencia empírica actual, cambiar el esquema de impuestos corporativos no afectaría el stock de capital deseado (Bustos et al., 2003), pero evidencia preliminar más reciente indica que un cambio en la tasa de impuestos podría tener algún efecto. Según Vergara (2004), cuya evidencia se ha utilizado para argumentar que se obtendrían grandes beneficios de una reducción de la tasa de impuestos corporativos, una reducción sustancial (de un 17 a un 10 por ciento) de la tasa de impuestos corporativos en Chile aumentaría la tasa de inversión entre 2 y 3 puntos porcentuales. Aun así, tal aumento en la inversión, según los parámetros mencionados, aumentaría el crecimiento en sólo 0,15 a 0,21 por ciento anual ${ }^{4}$.

\subsection{Fuentes de crecimiento económico}

El crecimiento económico resulta de un aumento en la cantidad de uno o ambos factores de producción, el trabajo y el capital, o de un aumento en la productividad total de factores (PTF). En este sentido, una primera manera de examinar la experiencia del crecimiento es separar el aporte de los aumentos en el trabajo y el capital y el aporte de la PTF, utilizando el método desarrollado por Solow (1957), considerando la siguiente función de producción, que transforma el trabajo (L) y el capital (K) en producto (Y):

$$
Y=A F(K, L) \text {, }
$$

${ }^{4}$ Sin embargo, el hecho de que los efectos podrían ser pequeños no debe utilizarse como argumento para elevar los impuestos a las corporaciones. La evidencia que se examina en este texto es muy parcial. No considera los efectos de los impuestos corporativos en la economía, especialmente en la dinámica del ahorro. Mi lectura de la literatura actual sobre la hacienda pública es que el impuesto al capital en general es malo; sin embargo, no se ha hecho ninguna investigación comprehensiva sobre este tema para la economía chilena. En todo caso, lo importante aquí es que el tema de cómo estimular la inversión es mucho más sutil y complejo que lo que sugieren los debates populares. Se necesita más investigación para poder evaluar plenamente los efectos del sistema de impositivo en el crecimiento y cómo se puede mejorar para promoverlo. 
donde $A$ representa la PTF. Un aumento en la PTF implica que la economía puede producir más con la misma cantidad de factores. Asumiendo que la función de la producción exhibe retornos constantes a escala, y que los mercados de factores y bienes son competitivos, podemos expresar el cambio en el producto $\left(\frac{\Delta Y}{Y}\right)$ como:

$$
\frac{\Delta Y}{Y}=\alpha \frac{\Delta K}{K}+(1-\alpha) \frac{\Delta L}{L}+\frac{\Delta A}{A} .
$$

El parámetro $\alpha$ representa la participación de capital en el ingreso total y 1 - $\alpha$ la participación del trabajo. Entonces, la ecuación (2) nos permite calcular los aportes de capital, trabajo y PTF al crecimiento del producto.

El Cuadro $\mathrm{N}^{\circ} 4$ presenta una desagregación para Chile del período 1970-2004. Para la participación del ingreso del trabajo se usa un valor de 0,6 , una cifra bastante mayor a lo que sugiere las cuentas nacionales, pero menor a la que sugiere la evidencia internacional ${ }^{5}$. Los resultados no cam-

CUADRO No 4: $\quad$ FUENTES DE CRECIMIENTO ECONÓMICO, 1970-2004 (1)

\begin{tabular}{lcccr}
\hline & $\begin{array}{c}\text { Crecimiento } \\
\text { del producto }\end{array}$ & Capital & $\begin{array}{c}\text { Aporte de } \\
\text { trabajo }\end{array}$ & PTF \\
\hline $1970-74$ & 0,93 & 1,16 & 0,27 & $-0,49$ \\
$1975-79$ & 3,02 & 0,32 & 0,89 & 1,79 \\
$1980-84$ & 0,39 & 0,78 & 0,96 & $-1,34$ \\
$1985-89$ & 6,37 & 1,19 & 3,24 & 1,82 \\
$1990-94$ & 7,29 & 2,70 & 1,75 & 2,67 \\
$1995-99$ & 5,35 & 3,44 & 0,53 & 1,32 \\
$2000-04(2)$ & 3,69 & 2,04 & 0,81 & 0,79 \\
$1990-99$ & 6,32 & 3,07 & 1,14 & 1,99 \\
$1970-04$ & 3,83 & 1,66 & 1,20 & 0,93 \\
$1985-04$ & 5,67 & 2,34 & 1,58 & 1,65 \\
\hline
\end{tabular}

(1) Las cifras son promedios geométricos de datos anuales y la suma puede no ser igual al total.

(2) El año 2004 es estimado.

Fuente: Cálculos del autor, sobre la base de las cuentas nacionales oficiales. Supuestos: la participación del trabajo es igual a 0,6 y la depreciación del capital es igual a $6 \%$.

${ }^{5}$ Gollin (2002) argumenta que el valor menor que se obtiene de las cuentas nacionales surge del hecho de que el ingreso del trabajo es subestimado en las empresas pequeñas, y que, después de ajustarlo apropiadamente, la participación del trabajo es entre 0,65 y 0,8 . 
bian significativamente si se aumenta la participación del trabajo a 0,65. Para construir el stock de capital, ocupo el método de inventario perpetuo con una tasa de depreciación de un 6 por ciento.

Finalmente, $L$ se mide como empleo total, sin ajustar por la calidad de la fuerza de trabajo o el número de horas trabajadas por persona.

La evidencia muestra que en dos períodos de cinco años, el inicio de los años 70 y 80, la PTF descendió. Esto, sin embargo, revela los problemas típicos de medición, tales como la falta de un control representando la utilización de capacidad y la acumulación de trabajo (labor hoarding), puesto que es poco probable que hubiese alguna regresión tecnológica. Otros estudios, examinados más adelante, siguen mostrando un crecimiento negativo en la PTF después de controlar tanto por la calidad del capital y el trabajo, como por la utilización de la capacidad, aunque no controlada por la utilización del empleo. El cuadro muestra un aumento en el aporte de la PTF desde mediados de los 80: el crecimiento de la PTF alcanzó un máximo de 2,7 por ciento anual en el quinquenio 1990-1994, lo cual es bastante alto según los estándares internacionales.

Un rasgo interesante de este registro del crecimiento económico de Chile está conformado por las dos fases distintas de la época dorada. La primera ocurrió durante la segunda mitad de los 80, y la segunda en los 90. En la primera fase, después de recuperarse de la recesión de 1982, hubo un fuerte repunte en el empleo. La tasa de desempleo comenzó en torno a 30 por ciento durante la crisis de 1982, para luego caer a cifras de un solo dígito hacia fines de la década. Durante la segunda mitad de los 80, no menos de la mitad del crecimiento del PIB de Chile se explica por el aumento en el empleo. Después de que el desempleo cayera a niveles normales, el crecimiento PTF durante los 90 promedió un 2 por ciento anual, que no es significativamente más alto que la tasa de crecimiento de fines de los 80 . Su tasa de crecimiento en la segunda mitad de los 80 también fue muy similar a la de los 90 en su conjunto (Cuadro $\mathrm{N}^{\circ} 4$ ). Sin embargo, y en contraste con la segunda mitad de los 80 , durante los 90 casi la mitad de la tasa media de crecimiento de 6,3 por ciento anual reflejó la acumulación de capital, sostenida en tasas récord de inversión (formación bruta de capital fijo, en términos reales), como muestra el Gráfico $N^{\circ} 3$. Desde entonces, la tasa de inversión ha retrocedido levemente a aproximadamente 24 por ciento en años recientes. En resumen, la diferencia principal entre fines de los 80 y los 90 es que la recuperación de fines de los 80 se basó en la expansión del empleo, mientras que la de los 90 descansó en un alza importante en la 
inversión. El crecimiento del producto y de la PTF fueron similares en ambas fases $^{6}$. El Cuadro $\mathrm{N}^{\circ} 4$ permite concluir que el crecimiento rápido de Chile durante su época dorada se explica principalmente por la acumulación de factores, primero del trabajo y luego del capital. En contraste, el crecimiento de la PTF causó menos de 30 por ciento del crecimiento total, y en años recientes ha descendido a 20 por ciento.

Dejando de lado los temas de la medición, esta evidencia posibilita una interpretación optimista y otra pesimista. Por el lado negativo, muestra que el crecimiento de la PTF no ha sido el motor de este proceso de crecimiento; por el lado positivo, y como se examina más adelante, claramente queda mucho potencial para aumentar la productividad y por lo tanto el ingreso.

Para evaluar la robustez de estas conclusiones, el Cuadro $\mathrm{N}^{\circ} 5$ presenta estimaciones del crecimiento de la PTF de otros estudios, algunos de los cuales ajustan sus mediciones del trabajo por horas y calidad, y de capital por calidad y utilización. Beyer y Vergara (2002) y Gallego y Loayza (2002) obtienen resultados para el crecimiento de la PTF que son similares a los de este estudio, mientras Fuentes et al. (2004) informan valores un poco más altos ${ }^{7}$. Sin embargo, una estimación general adecuada es que el crecimiento aproximado de la PTF, durante la última década no ha sido superior a 2 por ciento anual.

CUADRO N 5: $\quad$ MEDICIONES ALTERNATIVAS DEL CRECIMIENTO DE LA PTF

\begin{tabular}{lcccc}
\hline Autores & Período & $\begin{array}{c}\text { Crecimiento } \\
\text { del producto }\end{array}$ & $\begin{array}{c}\text { Crecimiento } \\
\text { de la PTF }\end{array}$ & Ajustes* \\
\hline Beyer y Vergara (2002) & $1986-2001$ & 6,0 & 1,72 & No \\
Fuentes et al. (2004) & $1990-2003$ & 5,7 & 2,36 & No \\
Gallego y Loayza (2002) & $1986-2000$ & 6,6 & 1,95 & Sí \\
Fuentes et al. (2004) & $1990-2003$ & 5,7 & 2,47 & Sí \\
Este estudio & $1985-2004$ & 5,7 & 1,67 & No \\
\hline
\end{tabular}

* Ajustes por la utilización y la calidad de factores.

${ }^{6}$ Para una discusión de las políticas macroeconómicas que siguieron a la recuperación de la crisis de la deuda, véase Corbo y Fischer (1994).

7 Las diferencias en las tasas medias de crecimiento se deben al uso de promedios aritméticos versus geométricos, pero también a diferencias en las fuentes de los datos, y también si los datos utilizados son de las cuentas nacionales revisadas. 
Las cifras para el crecimiento de la PTF ofrecen una base para una estimación inicial del crecimiento potencial de Chile. Puesto que el modelo neoclásico predice que, en el largo plazo, el crecimiento del PIB per cápita es igual al crecimiento de la PTF dividida por la participación del trabajo, se podría extrapolar este resultado para predecir que el crecimiento potencial por habitante de la economía chilena sería aproximadamente 3,3 por ciento anual. Si agregamos la tasa de crecimiento de la población de 15 o más años, que desde 2000 ha promediado 1,7 por ciento anual, el crecimiento potencial del PIB puede estimarse en aproximadamente 5 por ciento anual. Por supuesto, esta estimación no considera el potencial para cerrar la brecha existente (catch-up), que podría aumentar el aporte de la PTF. Como se discute en la sección 5 , una tasa anual de crecimiento de un 5 por ciento es bastante cercana al nivel que otros métodos y estudios indican sería la tasa de crecimiento de Chile en el largo plazo, para las condiciones actuales. Cualquier investigador que examine los datos de fines de los 90, y ocupe el supuesto de un crecimiento en la PTF de largo plazo de un 3 por ciento anual (el promedio para 1990-1997 fue de 2,9 por ciento), concluiría fácilmente que el crecimiento de largo plazo sería cerca de 6,7 por ciento anual, que en retrospectiva se basaba en un muy alto supuesto de crecimiento de la PTF en términos de los estándares propios de Chile e internacionales.

\subsection{Diferenciales de ingreso}

El análisis anterior de las fuentes del crecimiento económico entrega un retrato razonable de las fuerzas impulsoras del aumento en el ingreso en Chile. Sin embargo, hay dos razones por las cuales es posible que esto no sea la forma correcta de desagregar el crecimiento. Primero, la teoría del crecimiento económico se refiere a las diferencias en el ingreso más que las diferencias entre las tasas de crecimiento. Segundo, desde un punto de vista más práctico, interesan las comparaciones internacionales y por esto es útil explicar las diferencias de ingreso entre países. Al medir las brechas en el stock de factores de producción y eficiencia (PTF), podemos explicar las diferencias de ingreso entre países. Para este propósito aquí hago una desagregación según “niveles”. En esta desagregación, y en contraste con la contabilidad de crecimiento que se presentó anteriormente, en vez de examinar la mano de obra no capacitada, se considera explícitamente el capital humano. Esto es relevante porque en la comparación entre niveles de ingreso es importante controlar por diferencias de la calidad de la fuerza de trabajo entre países. Este ejercicio compara el ingreso por habitante en Chile 
con el de EE.UU., como normalmente se hace en la literatura, y luego se desagrega la diferencia entre ellos para llegar a la brecha de productividad, la brecha entre capital y producto y la brecha de capital humano. En esto, se sigue la desagregación sugerida por Hall y Jones (1999), que es similar a la de Klenow y Rodríguez-Clare (1997).

Consideremos una función Cobb-Douglas de la producción, en el momento $t$ para el país $j$ :

$$
Y_{j t}=A_{j t} K_{j t}^{\alpha} H_{j t}^{1-\alpha},
$$

donde $A$ nuevamente representa la PTF, $K$ es el capital físico y $H$ es el trabajo, ajustado por el capital humano. El último puede rescribirse como $L h$, donde $L$ es empleo y h es una medición de capital humano por trabajador. Al utilizar las minúsculas para las variables per cápita (o más bien, por trabajador), y omitir el índice del tiempo, tenemos:

$$
y_{j}=A_{j} k_{j}^{\alpha} h_{j}^{1-\alpha} .
$$

Ahora podemos comparar los niveles de ingreso por habitante de dos países $j$ e $i$ como

$$
\frac{y_{j}}{y_{i}}=\frac{A_{j}}{A_{i}}\left(\frac{k_{j}}{k_{i}}\right)^{\alpha}\left(\frac{h_{j}}{h_{i}}\right)^{1-\alpha} .
$$

Podríamos simplemente utilizar esta desagregación, pero, como sabemos por la teoría del crecimiento, si ocurre un shock de productividad (esto es, si $A$ sube), aumentará la razón capital-trabajo en el estado estacionario, y entonces el aumento en la productividad será incorrectamente atribuido a un alza en la razón capital-trabajo. Sin embargo, lo que sí queda invariable en el caso de un aumento de productividad en el estado estacionario es la razón capital-producto, que depende de la tasa de inversión, la que a su vez depende de la tasa de ahorro. Entonces, un aumento en inversión llevará a un alza en la razón capital-producto, mientras un aumento en productividad no tendrá este efecto 8 .

Si volvemos a escribir la ecuación (4) en términos de la razón entre el capital y el producto, eso es, dividiendo y multiplicando el lado derecho por $y^{a} \mathrm{y}$ volviendo a arreglarlo, tenemos

${ }^{8}$ Para una visión escéptica de este método, ver Bosworth y Collins (2003), quienes argumentan que no todos los aumentos en el capital son resultado de aumentos en la PTF. 


$$
y_{j}=A_{j}^{1 / 1-\alpha}\left(\frac{k_{j}}{y_{j}}\right)^{\alpha / 1-\alpha} h_{j} .
$$

Finalmente, podemos considerar dos países y desagregar la brecha del producto entre ellos como:

$$
\frac{y_{j}}{y_{i}}=\left(\frac{A_{j}}{A_{i}}\right)^{1 / 1-\alpha}\left(\frac{k_{j} / y_{j}}{k_{i} / y_{i}}\right)^{\alpha / 1-\alpha} \frac{h_{j}}{h_{i}} .
$$

Aquí se compara con los EE.UU. (país i). Por lo tanto, si el producto por habitante resulta ser $Z$ por ciento el de EE.UU., entonces $Z_{a}$ por ciento puede explicarse como diferenciales de productividad, medido como el primer término en el lado derecho de la ecuación (7), $Z_{k y}$ por ciento por diferencias en la razón entre el capital y el producto, y $Z_{h}$ por ciento por las diferencias de capital humano. Por construcción, entonces $(1+Z)=\left(1+Z_{a}\right)$ $\left(1+Z_{k y}\right)\left(1+Z_{h}\right)^{9}$.

Finalmente, para medir el capital humano, ocupo la especificación tradicional basada en los retornos de la educación por año de escolaridad:

$$
h=e^{\phi E},
$$

donde $E$ representa los años de escolaridad y $\phi$ corresponde a los retornos que se pueden estimar ocupando las ecuaciones Mincer ${ }^{10}$. Luego, siguiendo a Hall y Jones (1999), se asume que el exponente de la ecuación (8) es ecuación por segmento lineal. Para los primeros cuatro años de la educación asigno un retorno de 13,4 por ciento, que es el retorno de la educación en África. Para los próximos cuatro años siguientes, ocuparé un retorno de 10,1 por ciento, y para más años ocupo el retorno de escolaridad de los países de la OCDE, que es 6,8 por ciento.

El resto de los datos se construye de la misma manera que la desagregación de Solow, ya descrita. Para las cuentas nacionales, ocupo la versión 6.1 de las Penn World Tables de Aten, Heston y Summers (2002),

${ }^{9}$ Las desagregaciones se construyen país por país, y, por lo tanto, cuando se toman los promedios entre países esta identidad puede que no se mantenga.

10 Tenemos $(1 / h)(d h / d E)=\phi$ es el retorno de la escolaridad. 
para poder contar con datos comparables internacionalmente. Los resultados se presentan en el Cuadro $N^{\circ}$ 6. El PIB per cápita de Chile en 2000 fue solo el 39 por ciento del de EE.UU., cuando se mide la PPC. La razón capitalproducto en Chile fue solo 14 por ciento inferior a la de EE.UU. y el capital humano fue 31 por ciento menor. La diferencia mayor se obtiene para la PFT, llegando a ser 35 por ciento menor que la de EE.UU. Por lo tanto, el factor más importante detrás de las diferencias con EE.UU. es la PFT, seguida muy de cerca por el capital humano ${ }^{11}$. Esto es consistente con los resultados de la contabilidad del crecimiento que muestran que, a pesar de los razonables niveles de crecimiento de la PFT, esta no explica más de 30 por ciento de la rápida tasa de crecimiento experimentada por Chile desde mediados de los 80 .

Si la PFT chilena fuera igual a la de EE.UU., la brecha de ingreso disminuiría de 61 por ciento a 40 por ciento; si en cambio, la razón capital-

CUADRO N 6: $\quad$ DESCOMPOSICIÓN DEL NIVEL DEL PIB PER CÁPITA 2000

\begin{tabular}{lcrrr}
\hline & $\begin{array}{c}\text { PIB } \\
\text { per cápita }\end{array}$ & Capital-producto & $\begin{array}{c}\text { Capital-trabajo } \\
\text { [razón] }\end{array}$ & $\begin{array}{c}\text { Productividad } \\
\text { de factores }\end{array}$ \\
\hline \multirow{4}{*}{ Chile } & & & & \\
& 0,389 & 0,863 & 0,694 & 0,649 \\
México & & {$[0,450]$} & {$[0,560]$} & {$[0,599]$} \\
& 0,381 & 0,922 & 0,684 & 0,604 \\
Corea & & {$[0,413]$} & {$[0,557]$} & {$[0,631]$} \\
& 0,571 & 1,185 & 0,977 & 0,493 \\
Asia-4 & & {$[0,482]$} & {$[0,584]$} & {$[1,158]$} \\
& 0,670 & 1,089 & 0,885 & 0,724 \\
América Latina & 0,212 & {$[0,640]$} & {$[0,788]$} & {$[0,963]$} \\
& & 0,728 & 0,581 & 0,430 \\
Asia & 0,260 & {$[0,250]$} & {$[0,313]$} & {$[0,423]$} \\
& & 0,960 & 0,768 & 0,339 \\
& & {$[0,260]$} & {$[0,325]$} & {$[0,737]$} \\
\hline
\end{tabular}

Las cifras entre paréntesis representa cuánto podría ser el diferencial de ingresos si este factor fuera igual a uno.

Fuente: Cálculos del autor basados en Aten, Heston y Summers (2002).

${ }^{11}$ Los datos para el capital humano están basados, exclusivamente, en las mediciones de logros educacionales de la fuerza de trabajo y no están ajustados por calidad. Éste es un supuesto implícito cuando se utiliza el mismo retorno de escolaridad entre países. Como se verá más adelante, existe evidencia de un nivel relativamente bajo de la escolaridad en Chile, que aumentaría la brecha de capital humano. 
producto fuese igual, la brecha bajaría solo 55 por ciento. Se obtiene el mismo patrón para los otros países; o sea, la mayor parte de la brecha se debe a la eficiencia (PTF), más que a la cantidad de factores. Por lo tanto, se obtendrían los mayores aumentos en términos del cierre de la brecha del ingreso al cerrar la brecha de productividad, esto es, al aumentar la eficiencia en el uso de los factores existentes de la producción, para producir más con los mismos insumos. Sigue muy de cerca en importancia el bajo capital humano. El cuadro también muestra que el milagro asiático ha resultado principalmente de la profundización de capital más que un aumento en la productividad, un punto que fue originalmente enfatizado por Young (1995).

\section{Crecimiento de largo plazo: Fortalezas}

Desde fines de los 80, ha habido una explosión en la literatura sobre los determinantes del crecimiento económico, lo cual ha sido posible gracias a la emergencia de grandes bases de datos que permiten comparar países, y el desarrollo de la teoría del crecimiento económico ${ }^{12}$. En esta sección, en vez de hacer regresiones entre países, identifico las áreas que son importantes para el crecimiento económico donde Chile es fuerte. También examino si estas fortalezas existían antes del período dorado. Esto ayudará a dilucidar cuáles son los factores que sustentan el despegue chileno.

La ventaja de esta estrategia es que en vez de depender de un solo conjunto de regresiones, se puede tomar una visión más amplia de una literatura muy abundante y fructífera. El problema con las regresiones entre países es que no pueden incluir todos los posibles determinantes del crecimiento. Primero, porque la disponibilidad de los datos, los grados de libertad y la colinealidad de los datos hace difícil incluir todos los candidatos potenciales. Adicionalmente, la teoría, en general, no ofrece razones para la inclusión de todas las variables. Por esto, la mayoría de los investigadores se abocan sólo a un cierto número de variables comenzando con algún indicador base (benchmark), hecho que impide obtener una evaluación completa. Más aún, al focalizar los detalles hay mayor espacio para un análisis más acucioso.

Finalmente, no quiero sugerir que las áreas que se examinan aquí como fortalezas no puedan ser mejoradas todavía más, sino solo que no se les puede atribuir un desempeño en el crecimiento menos que óptimo.

12 Véase Barro y Sala-i-Martin (2004) para un repaso reciente de la evidencia. 


\subsection{Baja inflación}

La inflación baja, o más ampliamente la estabilidad macroeconómica, es un factor importante que permite que el crecimiento sea más rápido ${ }^{13}$. La inflación distorsiona la asignación de recursos, desvía el tiempo y el talento desde la actividad productiva hacia los esfuerzos por protegerse contra la inflación, introduce ineficiencias en la asignación del crédito, y constituye un síntoma de instituciones y políticas macroeconómicas pobres. No hay evidencia en ninguna parte del mundo de crecimiento rápido sostenido en un ambiente de alta inflación.

En el caso de Chile, lo primero que hay que destacar es que existe una gran diferencia entre la inflación promedio entre el período que precede y el que sigue a 1985; la diferencia es particularmente llamativa para el período que se inicia a mediados de los 90 , cuando Chile logró por primera vez, desde que se mantienen estas estadísticas, mantener una inflación de un solo dígito. (Dos períodos previos con inflación de un dígito desde los 60 fueron muy breves, no más de dos años. Más aún, ambos períodos, uno al principio de los 60 y el otro al inicio de los 80, coincidieron con la época de regímenes de tasa de cambio fija que terminaron en un colapso.) Entre 1960 y 1990, la tasa promedio anual de inflación (diciembre a diciembre) fue de 72 por ciento, aunque ese promedio llega a 26 por ciento si se excluyen los años de inflación de tres dígitos (1972-1976). La historia de la inflación en Chile desde 1960 se presenta en el Gráfico $N^{\circ} 4$.

La reducción persistente de la inflación comenzó en 1990, y entre 2000 y 2003 la inflación promedió sólo 2,8 por ciento. La caída en la inflación fue el resultado de tres factores importantes. Primero, en 1989 la independencia del Banco Central de Chile fue concedida por una ley de rango constitucional, que establece la estabilidad de precios y el funcionamiento normal del sistema de pagos como sus objetivos. El Banco Central cuenta con la independencia en términos de sus instrumentos, objetivos y presupuestos. A su vez quedó prohibido que hiciera préstamos al gobierno. Segundo, la consolidación fiscal, que se examina más abajo, también fue clave para mantener la estabilidad y evitar un financiamiento inflacionario a través del dominio fiscal sobre la política monetaria. Finalmente, no menos importante fue el crecimiento en sí mismo. Una larga historia de inflación hizo que la economía chilena fuera muy resistente a los esfuerzos por lograr la desinflación. La indización basada en la inflación previa fue común. Los salarios

${ }^{13}$ De Gregorio (1992, 1996), Fischer (1993), y Barro (1997) encuentran que la inflación tiene un significativo efecto negativo en el crecimiento. 


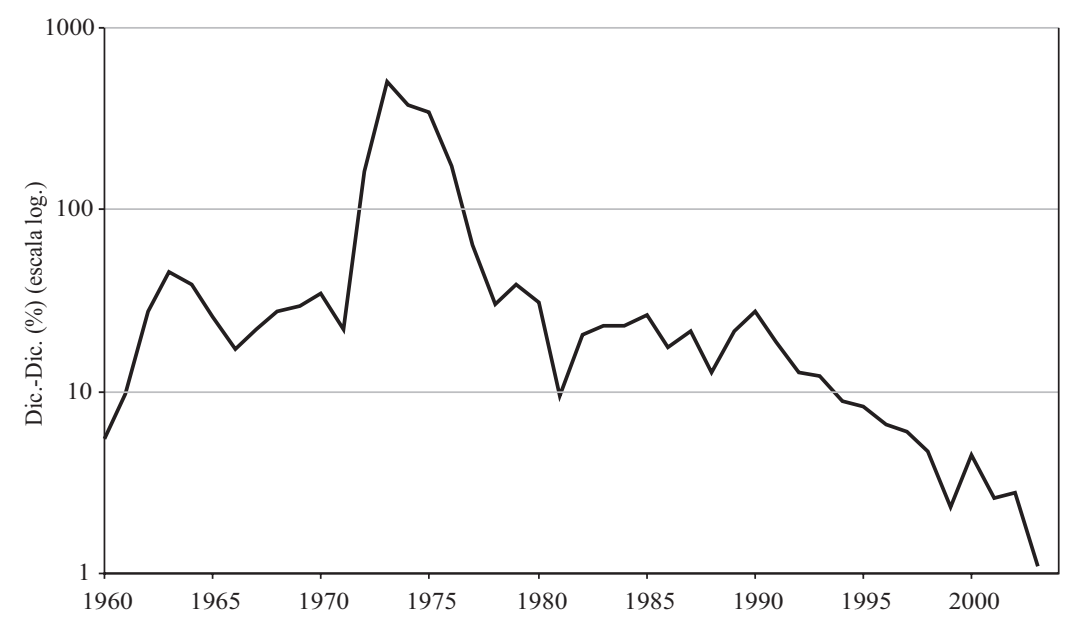

nominales, el centro de la banda cambiaria, los precios regulados y otros valores importantes, todos estaban asociados a la inflación pasada. Sin embargo, la alta tasa de crecimiento de la productividad chilena hizo posible una reducción en la inflación a pesar de la indización, puesto que el segundo dejó de ser una restricción activa en la medida que aumentaba el crecimiento (De Gregorio, 2004). Hubo un círculo virtuoso entre inflación y crecimiento, puesto que la baja inflación se convirtió en un factor que aumentó el crecimiento, mientras que el crecimiento hizo menos doloroso el esfuerzo por lograr la desinflación.

La inflación baja y en descenso ha sido un factor positivo que sostiene el crecimiento en Chile y, al mismo tiempo, una explicación parcial del despegue del crecimiento del país. Sin embargo, un problema de temporalidad debe examinarse: el crecimiento comenzó en 1985, pero la inflación comenzó a caer después. En este sentido, la hipótesis planteada anteriormente, de que los finales de los 80 fueron más un período de recuperación que de alto y persistente crecimiento cobra más fuerza. A fines de los 80 Chile carecía de acceso al financiamiento extranjero y tenía una tasa de cambio real muy depreciada. Una vez que la economía logró el pleno empleo, la estabilidad macroeconómica se tornó más relevante. Es difícil imaginar cómo Chile podría haber mantenido su crecimiento con inflación de dos dígitos.

Actualmente, la política monetaria en Chile opera dentro de un marco de objetivo de inflación, en el cual el Banco Central se compromete a mantener la inflación anual en una banda entre 2 y 4 por ciento al año, que 
converge hacia el centro de la banda en un horizonte de dos años. Mantener la inflación baja y estable es una base sólida para que la política monetaria aporte al crecimiento de largo plazo.

\subsection{Políticas fiscales sólidas}

La política fiscal ha sido otro factor importante para promover el crecimiento económico, y ha operado a través de dos canales. Primero, la política fiscal ha jugado un rol clave en lograr la inflación baja y la estabilidad macroeconómica que acabamos de examinar. Segundo, el tamaño del gobierno ha quedado en niveles que no inhiben el crecimiento económico.

El Gráfico No 5 muestra la trayectoria del déficit fiscal desde $1960^{14}$. Hasta 1974, Chile tenía un déficit fiscal persistente. El primer repunte ocurrió en la segunda mitad de los 70 y siguió con un deterioro relativamente modesto durante la crisis de 1982. Luego hubo una serie de superávits por 12 años consecutivos, con un deterioro durante la desaceleración después de 1998. En 2004 se regresó a un superávit fiscal a nivel del gobierno central. Por lo mismo, como la política antiinflacionaria, la disciplina fiscal no solo ha sido un factor detrás del crecimiento rápido del país, sino también forma parte de la explicación de las diferencias entre los períodos pre y post 1985. El presupuesto ha fluctuado algo, pero la consolidación fiscal claramente fue tomando fuerza después de mediados de los 70. Esta evidencia demuestra que más allá del aporte de la política en la moderación de las fluctuaciones cíclicas, el sector público hizo un fuerte aporte al crecimiento durante la época dorada y es, evidentemente, una de las fuentes de mayor fortaleza para el crecimiento futuro.

Otra indicación de la austeridad fiscal de Chile es el nivel de la deuda pública. El Gráfico N ${ }^{\circ} 6$ compara la deuda bruta del gobierno central con un número de países mayoritariamente de ingresos medios, revelando que la razón de deuda pública sobre PIB para Chile es muy baja. Los constantes superávits fiscales de fines de los 80 y casi todos los 90 han producido una fuerte baja en la deuda pública. En 1989, la deuda total del sector público consolidado (gobierno central más banco central ${ }^{15}$ ) llegaba a 73 por ciento

14 Las cifras no son totalmente compatibles, pero una mirada a las diferentes fuentes representan razonablemente el déficit fiscal del gobierno central durante los últimos 40 años. Las cifras vienen de Velasco (1994) hasta 1986, y de fuentes oficiales del Ministerio de Hacienda de allí en adelante. Una de las diferencias es que en el caso del segundo, a las series fiscales se les aplica el criterio de devengo, mientras en el primer caso se aplica el criterio de pago.

15 La deuda del banco central tuvo su origen en la crisis financiera de 1982 y luego aumentó debido a la acumulación de reservas durante los 90 . 
GRÁFICO No 5: CHILE: BALANCE FISCAL 1960-2003

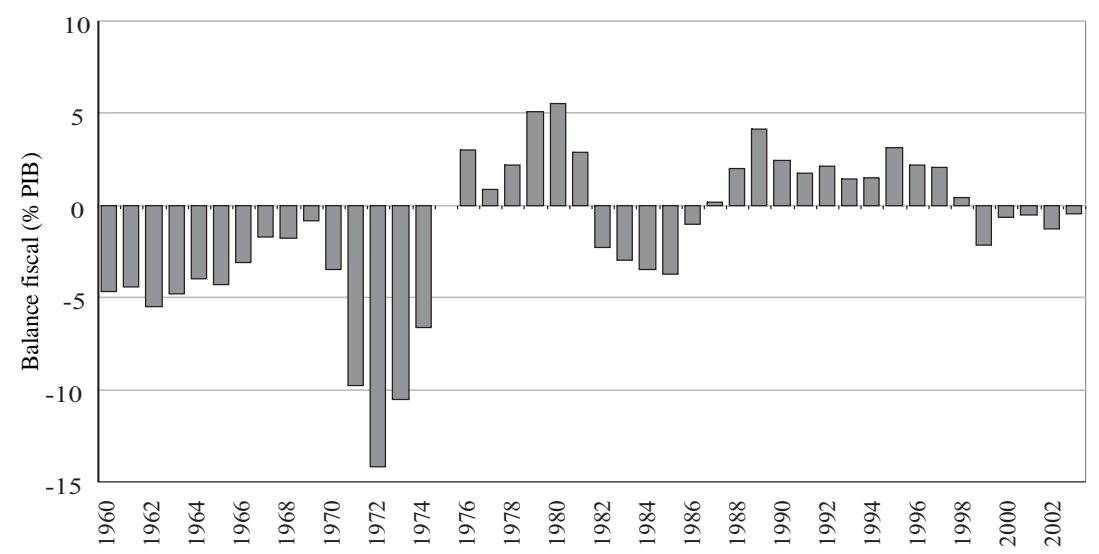

GRÁFICO No 6: DEUDA PÚBLICA EN PAÍSES SELECCIONADOS, 2002

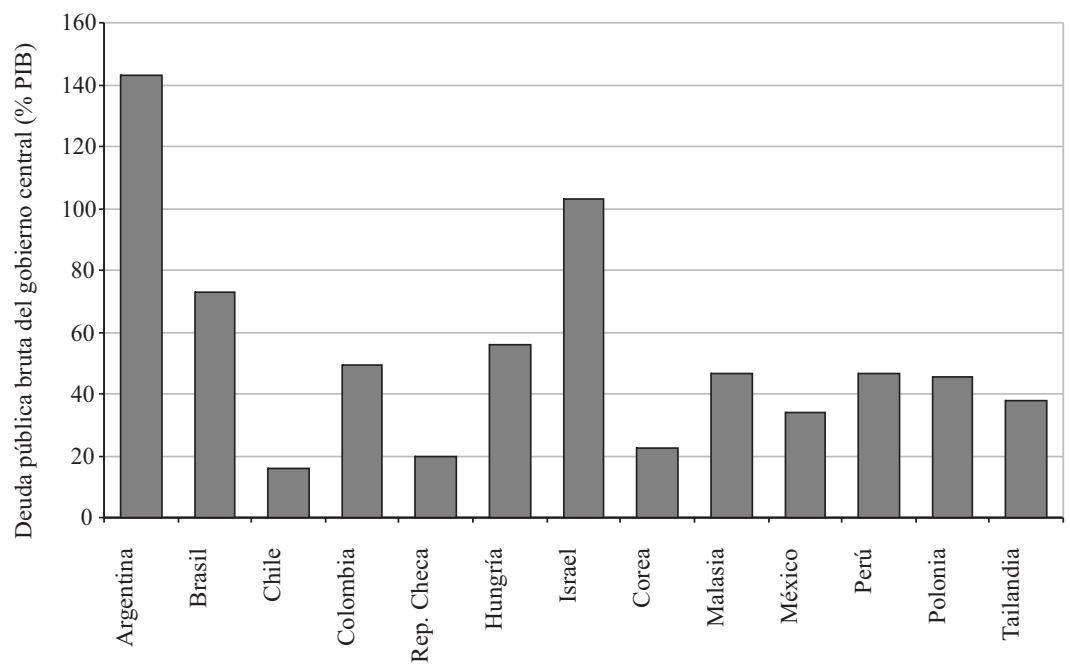

del PIB en términos brutos y 40 por ciento en términos netos. La deuda ha caído brusca y persistentemente desde entonces, y en 2003 la deuda bruta llegaba a solo 34 por ciento del PIB, y la deuda neta un mero 7 por ciento. Gracias a este logro, Chile tiene un nivel de deuda pública entre los más bajos de los países con pleno acceso al capital financiero internacional. Un resultado de esto es que el spread del interés entre la deuda pública de 
Chile y los bonos del tesoro de EE.UU. ha caído por debajo de los 100 puntos base.

Actualmente, la regla de mantener un superávit estructural (ajustado al ciclo) del Gobierno central en un uno por ciento del PIB ha fortalecido el compromiso con la responsabilidad fiscal. Permite la operación de estabilizadores automáticos y el uso de una política fiscal anticíclica, lo cual es algo inusual entre los países en desarrollo, especialmente los de América Latina (Gavin y Perotti, 1997).

Estas comparaciones internacionales llevan a una conclusión clara: Chile en términos fiscales, es uno de los países más responsables del mundo. Pero la política fiscal en Chile también ha tenido otro impacto más estructural en el crecimiento económico, al mantener el tamaño del gobierno relativamente acotado y con una composición del gasto gubernamental que favorece el crecimiento. Esto refleja la visión de que la inversión pública, la educación, y ciertas otras formas de gasto son buenas para el crecimiento económico y que lo que es dañino para el crecimiento es el gasto gubernamental no productivo.

Como una comparación internacional simple (y manteniendo presente las advertencias y las dificultades implícitas en este tipo de comparación), el Gráfico $\mathrm{N}^{\circ} 7$ ocupa datos fiscales del World Development Indicators del Banco Mundial para 2004. Puesto que un ingreso mayor por habitante se asocia con una mayor participación del gobierno en el PIB, el gráfico presenta varios indicadores del gasto gubernamental para varios países contra su PIB por habitante, medido según precios internacionales actuales ajustados por PPC, y compara el tamaño del gobierno chileno con el que se esperaría de acuerdo con su nivel de ingreso (como indica la línea de regresión en cada panel) ${ }^{16}$. Los dos paneles superiores muestran el gasto total del gobierno y el gasto corriente total sobre el PIB por habitante. En ambos casos, el tamaño del gobierno chileno es aproximadamente un 5 por ciento del PIB por debajo del nivel que se esperaría para un país con el nivel de ingreso que tiene Chile. (Se obtendría una conclusión similar si hubiésemos tomado una medida más estrecha del gasto, como por ejemplo el consumo final del gobierno de bienes y servicios.) Así se puede concluir que el tamaño del gobierno chileno no puede haber sido negativo para el crecimiento del país ${ }^{17}$.

${ }^{16}$ Los datos en el gráfico son de 1998, aunque World Development Indicators tiene datos hasta 2000. Los resultados si se ocupan los datos de 2000 no difieren, pero la cobertura internacional es mucho menor.

17 Barro (1999) también notó esto. 


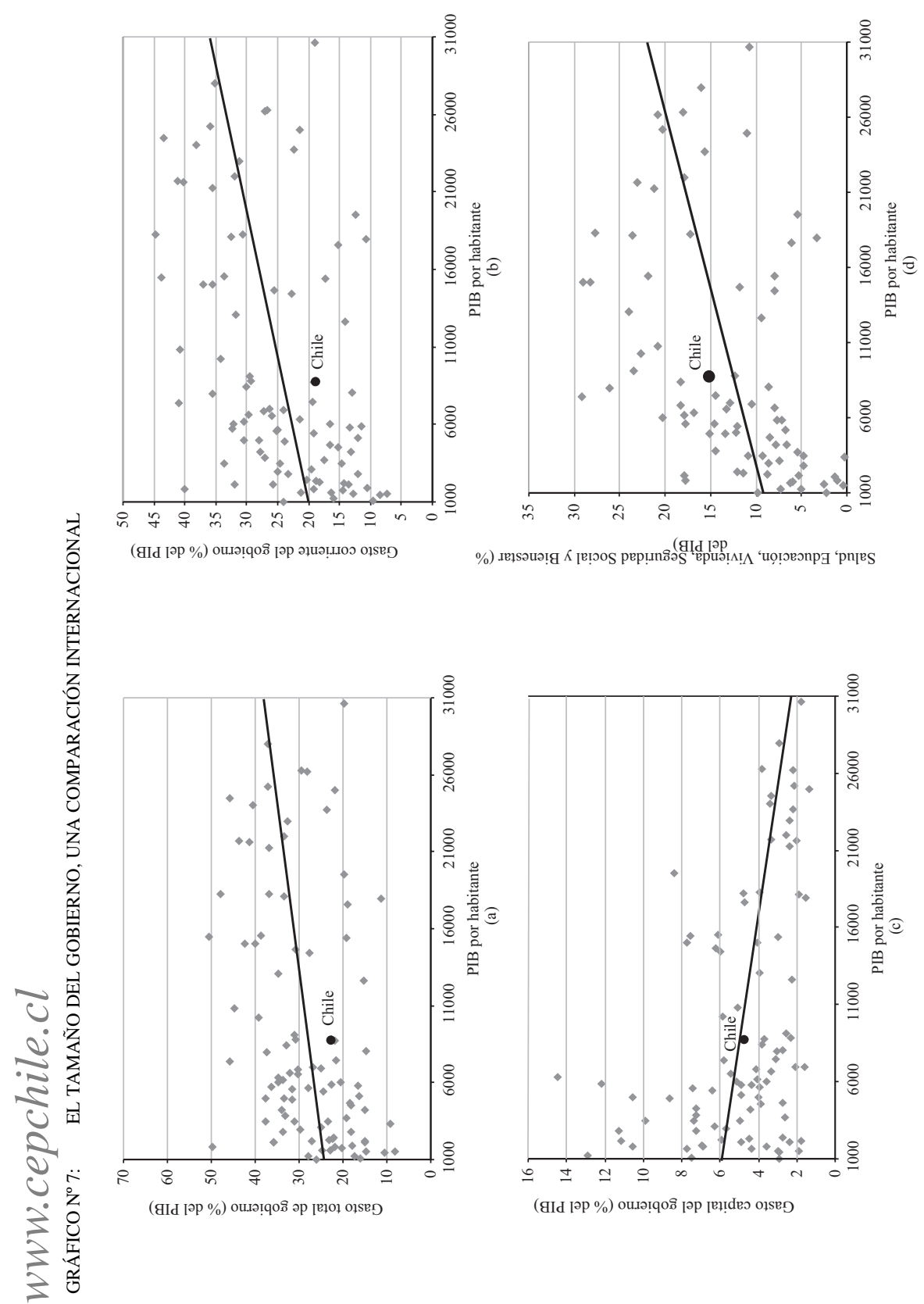


Los dos paneles inferiores del Gráfico $\mathrm{N}^{\circ} 7$ muestran que en Chile la composición del gasto gubernamental se inclina más hacia el crecimiento. En el caso del gasto capital, el gráfico muestra una relación negativa con el ingreso por habitante, y que Chile está aproximadamente en el punto indicado por su nivel de ingreso. Sin embargo, puesto que el tamaño del gobierno de Chile como un todo es algo más pequeño de lo que le correspondería de acuerdo a su nivel de ingreso, se puede inferir que el presupuesto se inclina más hacia la inversión pública que el de otros países, un factor que debería aportar positivamente al crecimiento. Más aún, el hecho de que Chile tiene un programa ambicioso de privatización de la infraestructura vial, implementado durante la segunda mitad de los 90, sugiere que la inversión total en infraestructura es mucho mayor de lo revelado por las cifras de inversión pública.

La evidencia relacionada con el gasto social es bastante más definitiva. El panel inferior a la derecha del Gráfico $\mathrm{N}^{\circ} 7$ muestra que en Chile el gasto público en educación, salud, seguridad social y bienestar es alto dado el nivel de ingreso del país. En la medida que el gasto en educación y salud mejora la calidad de capital humano, debería correlacionarse positivamente con el crecimiento. En este gráfico, sin embargo, los gastos en educación y salud están combinados con el de otros gastos sociales cuyo impacto en el crecimiento no está claro ${ }^{18}$. Sin embargo, y como se examina más abajo, el gasto social en Chile ha ayudado a compensar la distribución desigual del ingreso en el país. Más aún, es poco probable que cambiarían mucho las conclusiones si pudiésemos desagregar los datos, puesto que el gasto público en seguridad social sería relativamente bajo comparado internacionalmente ${ }^{19}$. El sistema de seguridad social fue privatizado a comienzos de los 80 y el gasto actual del gobierno en esta área se dedica exclusivamente al pago de los jubilados que optaron por no cambiarse del antiguo sistema de reparto (pay-as-you-go).

En resumen, la posición fiscal neta de Chile, el tamaño limitado de su gobierno y la composición favorable del gasto público total han estimulado el crecimiento económico; también pueden ayudar a explicar por qué el despegue ocurrió a mediados de los 80 y no antes. Por supuesto, las mejoras en la eficiencia del gasto público, un compromiso permanente con un tamaño de gobierno más bien acotado, y mejoras en los aspectos cíclicos de la política fiscal dentro de la regla fiscal mejoraría aún más el potencial de crecimiento del país.

${ }^{18}$ Asignado apropiadamente, sin embargo, el gasto social debería aumentar el bienestar.

19 No tengo conocimiento de datos que entreguen una completa comparación internacional del gasto social excluyendo la seguridad social. 


\subsection{Sector financiero fuerte}

Un sistema financiero que funciona bien es clave para canalizar los fondos disponibles hacia proyectos eficientes de inversión, y la evidencia empírica sobre crecimiento económico demuestra que la presencia de mercados financieros profundos favorece el crecimiento (véase, por ejemplo, Levine, 2004). Por supuesto, un sistema financiero profundo pero mal regulado puede ser muy malo para el crecimiento, puesto que puede servir de fuente o amplificador de las crisis, como de hecho Chile aprendió de su propia experiencia.

Hacia fines de los 70, Chile comenzó un ambicioso proceso de liberalización financiera, el que combinado con una tasa de cambio fijo y regulaciones poco prudentes, derivó en un rápido aumento del crédito financiero que el sistema bancario otorgara al sector privado. La garantía implícita del gobierno al sistema bancario, el seguro que se proporcionó a través del compromiso con el tipo de cambio fijo y una inadecuada regulación financiera (en especial, el no regular correctamente los préstamos entre instituciones relacionadas) generaron vulnerabilidades claves en el sector financiero y la economía como un todo. Esta debilidad, combinada con un severo shock externo en 1982, derivó en una profunda crisis bancaria y de la moneda, cuyo costo se ha estimado en 35 por ciento del PIB (Sanhueza, 1999).

El colapso del sistema financiero creó las condiciones para la ley de bancos de 1986, luego enmendada en los $90^{20}$. Quizás una de las reformas principales fue restringir los préstamos entre entidades relacionadas, una práctica que estuvo en el centro de la crisis de 1982. Adicionalmente, se introdujeron varios otros mecanismos para crear un sistema de regulación más prudente. Estos hitos, más la recapitalización del sistema bancario permitió la expansión de las actividades bancarias dentro de un ambiente financiero menos vulnerable.

Actualmente, la fortaleza del sistema bancario se clasifica entre los mejores de los mercados emergentes. El Gráfico $\mathrm{N}^{\circ} 8$ muestra un reciente ranking de los sistemas bancarios de diferentes países. El gráfico está basado en el índice promedio por país de Moody's. El sistema financiero de Chile se evalúa en un nivel similar al de los países industrializados. De los 61 países examinados, Chile ocupa el lugar 22, por encima de todos los otros mercados emergentes. Asimismo, en términos de cartera vencida, rentabilidad sobre activos y la razón de patrimonio sobre activos (que no se mues-

20 Para mayores detalles del marco institucional que ha apoyado el desarrollo del sistema bancario, véase Fuentes y Maquieira (2001). 


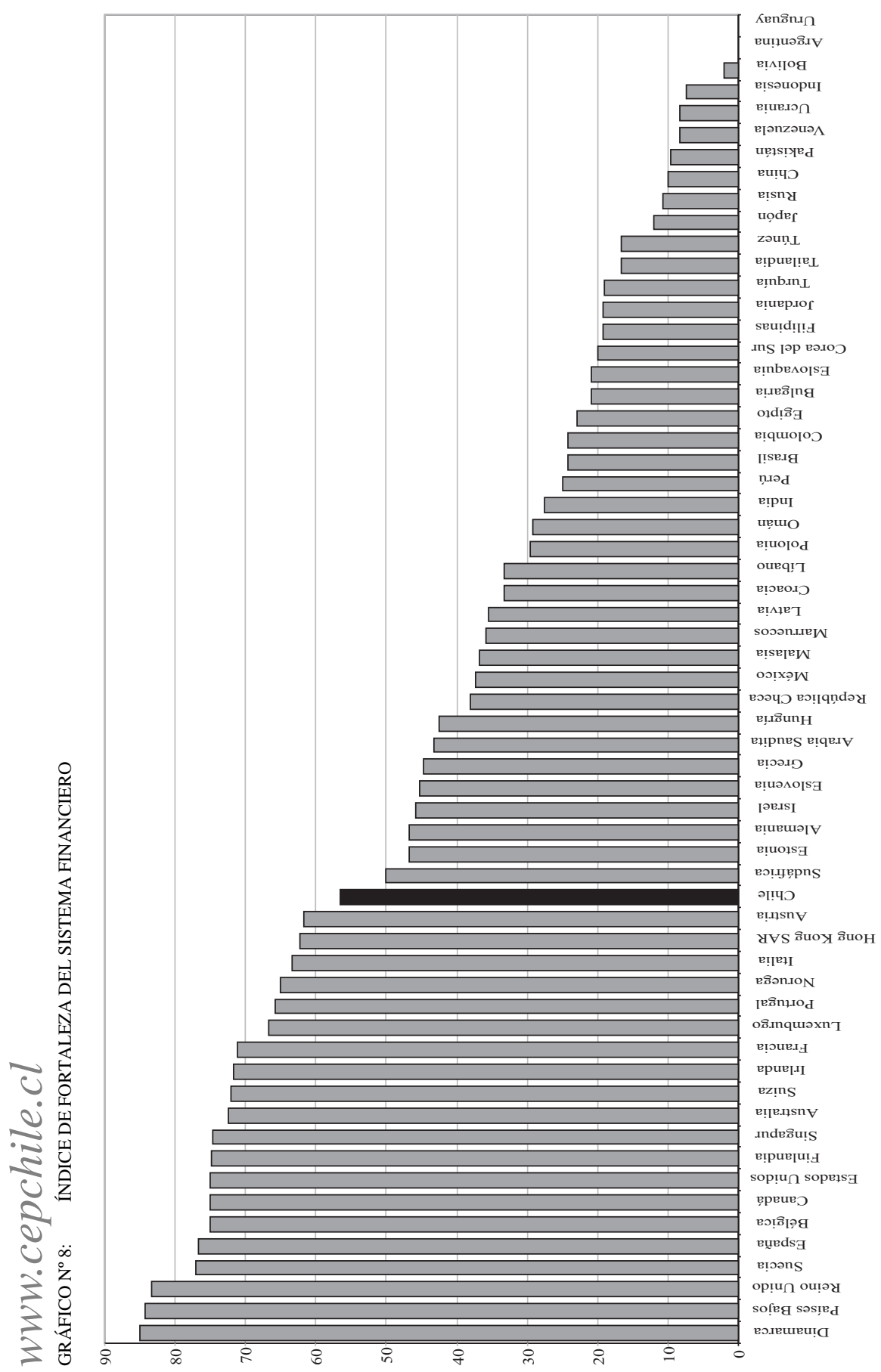


tran), Chile goza de algunos de los puntajes más altos entre los mercados emergentes.

El sector bancario chileno es muy activo en la intermediación de fondos. Expresado como un porcentaje del PIB, el crédito al sector privado es el más alto en América Latina, llegando a 65 por ciento en 2002, similar al nivel de algunos países industrializados. El mercado financiero en Chile está constituido principalmente por los bancos. Sin embargo, los inversionistas institucionales, especialmente los fondos de pensión, que administran una cartera equivalente a 50 por ciento del PIB, también han jugado un papel importante en el desarrollo del mercado de capitales en Chile. Más recientemente, los bajos costos financieros tanto como las nuevas leyes para facilitar el desarrollo financiero han llevado al desarrollo de un mercado profundo para bonos corporativos de renta fija. Nuevas formas de financiamiento, tales como factoring, bonos convertibles, leasing y efectos de comercio también han emergido. Finalmente, se aprobó una ley protectora de accionistas a principios de los 2000 para regular las ofertas públicas de acciones. Todas estas innovaciones deberían promover un mayor desarrollo financiero del país, un factor clave para asegurar que los buenos proyectos de inversión cuenten con financiamiento suficiente.

Otro aspecto positivo del desarrollo financiero de Chile ha sido su plena integración a los mercados financieros internacionales. Después de una historia de controles de capital, todos fueron eliminados en 1999, como resultado de la evolución de la política macroeconómica que, más allá de la regulación prudente del sistema financiero, introdujo un régimen de tipo de cambio flexible.

Tal como ocurre con la política monetaria y fiscal, la fortaleza y la profundidad del sistema financiero chileno data de mediados de los 80. Por lo tanto, el desarrollo financiero de Chile no solo ofrece la base de crecimiento futuro, sino que, además, ayuda a explicar el despegue del país. Sin embargo, sería una exageración decir que todo está tan bien como se podría esperar del sistema financiero. Como veré en detalle más adelante (sección 3.5), un reciente estudio del Banco Mundial explorando la facilidad de hacer negocios en los países en desarrollo, reveló que un problema de Chile es el alto costo de generar garantías (colateral). Esto no se ha traducido en un subdesarrollo financiero, pero claramente constituye un área que podría mejorarse para aumentar la intermediación, especialmente para las empresas pequeñas y medianas, que enfrentan los mayores problemas para constituir garantías. 


\subsection{Apertura al comercio internacional}

Una explosión hacia fines de los 80 en la cantidad de investigaciones que exploran los factores determinantes del crecimiento produjo una amplia gama de resultados dispares, y la mayoría de los factores que inicialmente fueron identificados como promotores del crecimiento luego fueron cuestionados por los estudios subsecuentes. Pero dentro de esta plétora de resultados, si hay un tema que goza de un consenso amplio (aunque de ninguna manera total), es que la apertura al comercio exterior fomenta el crecimiento económico. Las economías más abiertas han demostrado ser capaces de crecer más rápido que las cerradas. Esto es particularmente importante durante los períodos de liberalización del comercio exterior ${ }^{21}$. Además, después de una revisión minuciosa de la evidencia, Winters et al. (2004) mostraron que efectivamente la apertura está asociada a la reducción de la pobreza en el largo plazo, e incluso existe una fuerte presunción de que esto ocurre en el corto plazo. Naturalmente, la liberalización del comercio exterior puede también funcionar con algunas otras políticas para aliviar la pobreza. Por lo tanto, la liberalización del comercio exterior es buena para la economía y es aconsejable implementarla cuanto antes. (No se puede decir lo mismo de otras áreas, como por ejemplo la liberalización financiera).

Como fue documentado en De Gregorio y Lee (2004), el factor más importante que explica las diferenciales en las tasas de crecimiento entre América Latina y el Este de Asia durante los últimos 40 años ha sido la diferencia en el grado de apertura. Por supuesto, uno puede agregar muchas advertencias: la estrategia de apertura es muy relevante, así como también el marco institucional en el cual ocurre, pero es un hecho que las economías más abiertas crecen más rápidamente que las cerradas. Esta lección es particularmente importante para las economías pequeñas.

Además, la vieja idea que apoyaba la estrategia de sustitución de importaciones en América Latina en los 60, la cual argumentaba que una apertura al comercio llevaría a los países en desarrollo a producir bienes "malos" - principalmente productos primarios cuyos términos de intercambio bajarían - resultaron equivocados. Es verdad que los países que enfrentan términos de intercambio desfavorables crecen menos, pero también es cierto que los términos de intercambio no se han deteriorado tanto. Al comparar el comportamiento de las economías del Este de Asia y América Latina, De Gregorio y Lee (2004) encontraron que el comportamiento de los

${ }^{21}$ Para una revisión reciente y comprensiva de los datos y la evidencia adicional acerca de los efectos de la liberalización del comercio, ver Wacziarg y Welch (2003). Véase también Dollar y Kraay (2002) y Edwards (1997). Para una visión más escéptica, véase Rodríguez y Rodrik (2001). 
términos de intercambio no explica una parte significativa de la diferencia en el crecimiento. La industrialización orientada hacia adentro no ha sido una buena idea.

La apertura de la economía chilena fue una de las reformas más importantes, sino la más importante, de las aplicadas por el régimen militar en los 70 y los 80. En 1973, la tarifa promedio llegaba a un 100 por ciento, y existían múltiples tasas de cambio, con una razón de 1 a 52 entre la tasa más baja y la más alta. El proceso de liberalización del comercio que siguió al golpe militar fue rápido. Ya en 1979 la tasa de la tarifa aduanera estaba pareja en 10 por ciento ${ }^{22}$. Se eliminaron todas las barreras no tarifarias y se unificó el mercado cambiario.

Después de la crisis de la deuda, ocurrió una liberalización del comercio exterior, que comenzó en marzo de 1983 y culminó en mayo de 1985 con una tarifa plana de 35 por ciento. Pero dentro de un par de meses se bajaron nuevamente las tarifas, y llegaron a 15 por ciento en 1988. En 1991, las tarifas se redujeron a 11 por ciento, en un acto que algunos consideraron una de las señales más importantes del compromiso del nuevo gobierno democrático con la apertura al comercio. Comenzando en 1999, las tarifas se siguieron reduciendo, por 1 punto porcentual al año, desde 11 por ciento hasta su nivel actual de 6 por ciento.

Mientras tanto, Chile ha firmado una serie de acuerdos de libre comercio (ALC) con sus socios comerciales. De hecho, con la excepción de México, Chile ha firmado más ALC que cualquier otro país en el mundo. El interés de Chile en los ALC se hizo evidente al principio de los 90, cuando se anunció la intención de negociar un ALC con EE.UU. Después de la Cumbre de las Américas al principio de los 90, se anunció las conversaciones que llevarían a un ALC de todas las Américas, pero aún se implementa. Chile firmó varios otros ALC en los 90, y finalmente, en 2003, firmó un acuerdo con EE.UU. y otro con la Unión Europea. Estos ALC han reducido la tarifa efectiva de Chile más allá de la tarifa plana oficial. En 2004, la tarifa promedio había llegado a alrededor de 2,0 por ciento (Cuadro $\mathrm{N}^{\circ} 7$ ).

La apertura al comercio internacional de Chile ha aumentado sustancialmente con los años (Gráfico $\mathrm{N}^{\circ}$ 9), y hoy Chile está muy integrado en la economía mundial. El comercio total, medido como exportaciones + importaciones en términos nominales, llegó a 70 por ciento del PIB en 2003, y ha promediado 60 por ciento del PIB desde $1996^{23}$.

${ }^{22}$ Siempre han existido algunas excepciones, como por ejemplo los automóviles.

${ }^{23}$ Los datos más recientes incluidos en este gráfico están basados en los precios domésticos de 1986, que sobreestimarían la participación del comercio, pero no obstante la fuente de los datos, la tendencia en cuanto a la participación del comercio siempre va en aumento. 
CUADRO N $\mathrm{N}^{\circ}$ : $\quad$ ARANCELES (\%)

\begin{tabular}{lrrrrrrrrrr}
\hline & 1995 & 1996 & 1997 & 1998 & 1999 & 2000 & 2001 & 2002 & 2003 & 2004 \\
\hline General & 11,0 & 11,0 & 11,0 & 11,0 & 10,0 & 9,0 & 8,0 & 7,0 & 6,0 & 6,0 \\
Efectivo & 9,5 & 8,9 & 7,9 & 7,7 & 7,1 & 6,1 & 5,2 & 4,5 & 2,7 & 2,0
\end{tabular}

Fuente: Banco Central de Chile.

Un tema importante en el desarrollo del comercio chileno ha sido su concentración en el cobre. Sin embargo, a pesar de la gran abundancia del cobre en Chile su importancia ha disminuido. Como muestra el Gráfico $\mathrm{N}^{\circ}$ 9, entre 1960 y 1975 el cobre llegaba a 70 por ciento de las exportaciones totales, pero esta participación ha caído hasta menos de 40 por ciento en años recientes. Otras medidas de la concentración de las exportaciones, como por ejemplo los índices Herfindahl, también muestra un aumento en la diversificación, aunque el comercio exterior de Chile sigue siendo algo más concentrado que el de otros países (Villafuerte, 2004).

La permanente gravitación de las exportaciones de cobre en Chile no refleja el estancamiento del sector no cobre. Todo lo contrario, la inversión

GRÁFICO N ${ }^{\circ}$ 9: $\quad$ EXPORTACIONES TOTALES COMO PORCENTAJE DEL PIB Y DE LAS EXPORTACIONES DE COBRE

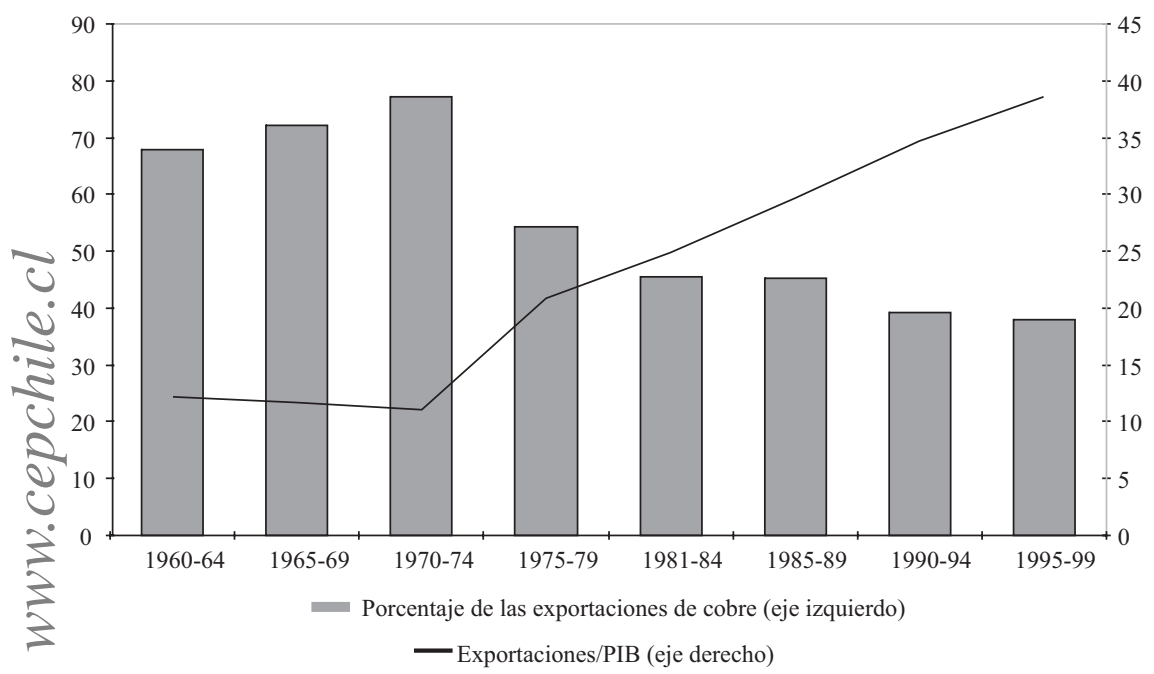


en la industria cuprífera fue muy activa durante los 90, condujo a una expansión de las exportaciones de cobre las que crecieron de 1,5 millón en 1990 a 4,8 millones de toneladas métricas en 2003. A pesar de este logro, la expansión de las otras exportaciones ha sido aún más dinámica, y es esta expansión la que da cuenta de la caída observada en la participación del cobre. El volumen de exportaciones totales creció a una tasa anual de 8,1 por ciento entre 1990 y 2003.

Como algunos economistas, notablemente Sachs y Warner (1995), han argumentado, más que una bendición una abundancia de recursos naturales puede resultar una maldición. Puede inducir a actividades que buscan renta (rent-seeking), desviar recursos escasos tales como el capital humano y físico de actividades que favorecen el crecimiento, o producir una apreciación real que resulta en la contracción de otros sectores transables. No hay evidencia de estos problemas en Chile. Las instituciones fuertes, incluyendo la disciplina fiscal, han evitado los efectos "voracidad". Una fuerza de trabajo educada y un pleno acceso a los mercados internacionales de capital han mantenido la inversión en otras actividades libre de impedimentos, y la tasa de cambio real ha quedado en niveles que no han impedido el despegue de las exportaciones. En resumen, no hay evidencia de que la abundancia de recursos naturales de la cual goza Chile haya sido un detrimento para el crecimiento; al contrario, ha elevado el ingreso y el bienestar del país ${ }^{24}$.

El Gráfico N ${ }^{\circ} 10$ demuestra que Chile comercia más por su tamaño que cualquier otro país latinoamericano y su razón de comercio-PIB es similar al de algunas economías asiáticas. Sin embargo, comparado con Asia (como se verá en la próxima sección), América Latina tiene relativamente poco comercio intrarregional, y, por lo tanto, el comercio dentro de la región no aporta mucho al aumento del comercio. No conozco un solo ejemplo de una economía pequeña y de ingreso relativamente alto que no esté integrada al resto del mundo, y este hecho por sí solo avala que la economía de Chile necesita ser muy abierta. La apertura al comercio impacta positivamente al crecimiento a través de muchos canales: permite la absorción de conocimientos, ofrece acceso a tecnologías nuevas y mejores, y fomenta la especialización y la explotación de economías a escala. Pero, desde mi punto de

${ }^{24}$ Bravo-Ortega y De Gregorio (2002) argumentan que cuando los recursos naturales inducen al escaso capital humano a abandonar las actividades favorables al crecimiento, el desarrollo de los recursos naturales podría reducir el crecimiento, pero no el ingreso. El nivel de capital humano en Chile es mayor al que gatilla estos efectos negativos, situación que no implica que este nivel sea suficiente. En la próxima sección, demuestro que a pesar de que este nivel puede ser consistente con el actual nivel de desarrollo, la calidad es relativamente baja. 
GRÁFICO No 10: PARTICIPACIÓN DEL COMERCIO PARA PAÍSES SELECCIONADOS

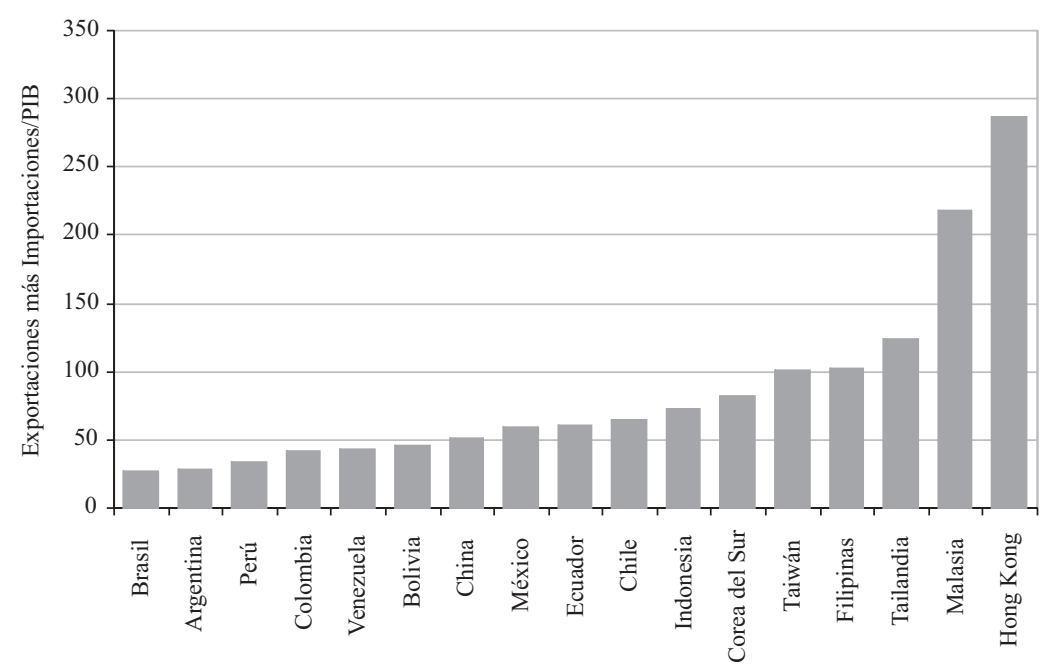

Fuente: Banco Mundial: Indicadores de Desarrollo Mundial, Departamento de Estadísticas de Taiwán, y Estadísticas de Singapur. Todas las cifras están expresadas en dólares del año respectivo.

vista, que naturalmente está basado en la experiencia chilena, dos factores adicionales son los más importantes. Primero, el comercio internacional abre muchas oportunidades de negocios nuevas e inesperadas, revelando ventajas comparativas que los emprendedores del país no percibían cuando su economía estaba cerrada. Segundo, el comercio obliga a los productores domésticos a ser eficientes, no solo para competir en los mercados mundiales, sino también para sobrevivir ante la presencia de competidores externos que operan en su propio país. Y esta eficiencia debe extenderse no solo a la producción de los bienes, sino también a las logísticas de la empresa, la distribución, el control de calidad, etc.

Algunos estudios han concluido que los ALC, especialmente aquellos con EE.UU. y Europa, tienen solo un pequeño efecto en el crecimiento y el bienestar. Esto puede sorprender a la luz de los comentarios iniciales ${ }^{25}$. La mayoría de las estimaciones existentes deben hacer fuertes supuestos acerca de las ganancias o las reducciones en los premios al riesgo asociadas a los ALC para encontrar efectos relevantes (aunque de todas maneras

${ }^{25}$ La evaluación más reciente se encuentra en Chumacero et al. (2003), quienes concluyen que en un estado de equilibrio el producto aumentaría en 1 por ciento, un resultado similar a los de simulaciones estáticas de Coeymans y Larraín (1994). 
pequeños). La razón técnica es que las estimaciones básicamente simulan pequeñas reducciones en las tarifas. Sin embargo, existen muchas ganancias dinámicas del comercio que no son fáciles de modelar, tales como los efectos de una mayor eficiencia y absorción de conocimientos. Además, el proceso de negociación de un ALC con países industrializados involucra una completa revisión del marco institucional del país, además de los cambios específicos, necesarios para la implementación de los acuerdos nuevos. A menudo se ignoran los impactos de los cambios institucionales.

Finalmente, los ALC ofrecen un acceso abierto y garantizado a mercados más amplios y profundos del mundo. Por esto, los ALC firmados por Chile con EE.UU. y la Unión Europea, y las nuevas negociaciones en Asia, se cuentan entre las más importantes iniciativas de política económica de los últimos 20 años.

\subsection{Instituciones fuertes y la regulación de los negocios}

Una creciente literatura ha enfatizado el rol de las instituciones y la gobernabilidad como factores claves para fomentar el crecimiento. Las instituciones que protegen los derechos a la propiedad y asignan eficientemente los recursos son esenciales para incentivar la acumulación de capital humano y físico, además de apurar el crecimiento de la productividad. La asignación de los talentos dentro de una economía es un determinante importante de su crecimiento potencial ${ }^{26}$. Una economía en la que las distorsiones incentivan un comportamiento de búsqueda de rentas producirá una dedicación a actividades no productivas. La capacidad de hacer valer los contratos y asegurar reglas de juego estables también es necesaria para el crecimiento. Por lo tanto, el crecimiento y la prosperidad se apoyarán en las instituciones que protejan los derechos a la propiedad y regulen y limiten la intervención del estado.

Se han desarrollado varios indicadores que buscan medir la gobernabilidad, la calidad del gobierno, la capacidad de garantizar los derechos a la propiedad, y otros aspectos que reflejan la calidad institucional. Ya he examinado algunos otros rasgos institucionales, tales como el tamaño del gobierno y la independencia de la política monetaria, que directamente influyen en las variables económicas tradicionales. Ahora me ocuparé de otros

${ }^{26}$ Para revisiones recientes véase Acemoglu et al. (2004) y Kaufmann y Kraay (2002). El énfasis en la geografía en vez de las instituciones se discute en Sachs (2003); acerca del papel del capital humano como una causa más fundamental del crecimiento que las instituciones, véase Glaeser et al. (2004). 
dos aspectos de las bondades institucionales. El primero consiste en los indicadores usualmente relacionados con la buena gobernabilidad, tales como la corrupción, el respeto a la ley, y el riesgo de expropiaciones. Estos pueden considerarse como características que protegen los derechos a la propiedad. Pero, además, es importante que las instituciones incentiven la creación de negocios y la capacidad emprendedora. Las restricciones al mercado del trabajo, las regulaciones a la entrada de nuevos negocios y la calidad de las políticas del gobierno también son relevantes para inducir a la acumulación de capital. Para este propósito, examinaré el índice de hacer negocios ("Doing Business Index", DBI) creado recientemente por el Banco Mundial (2004). Aunque estos índices son recientes, al mirarlos junto a los datos más antiguos sobre corrupción y el imperio de la ley se ve que la mejora en la calidad de las instituciones chilenas sin duda fue un aporte al despegue, a mediados de los 80 .

Chile ocupa el vigésimo lugar entre los 133 países menos corruptos, como se ve en la muestra incluida en el Gráfico $\mathrm{N}^{\circ} 11$. El índice de corrupción, que le da un valor de 10 al país menos corrupto y 0 para el más corrupto ordena los países según el grado de corrupción que se percibe entre los funcionarios oficiales y políticos. Los únicos países que superan a Chile en este índice son los industrializados y, con la salvedad de Hong Kong y Singapur, Chile se ubica por encima de las otras economías de América Latina y de Asia, e incluso de algunas de mayores ingresos.

Se obtienen rankings parecidos para el índice que mide el estado de derecho, preparado por International Risk Guide. En 2000, Chile se ubicaba en el puesto 23 de 112 países en esta medición. Este índice está disponible para un período mayor que el de la corrupción, con datos provenientes de la época previa a 1985. Los datos para 1980 ubicaban a Chile en el puesto 22 de 92 países. No hay datos comparables para los años anteriores, pero el nivel de Chile en 1980 indica que el país ya tenía instituciones fuertes incluso antes del despegue; por lo tanto, no se puede argumentar que fuera la construcción de fuertes instituciones las que ayudaron a estimular el crecimiento después de 1985.

Sin duda Chile cuenta con una larga tradición de buenas instituciones. El éxito de las reformas durante el régimen del general Augusto Pinochet fue el resultado no solo de buenas políticas económicas apoyadas por un gobierno dictatorial; para estos logros también fue clave la existencia de una sólida institucionalidad y debe servir de advertencia a otros países que podrían apurarse en efectuar reformas sin contar con un sólido marco institucional. De hecho, como dice Valenzuela (1994, p. 417): 


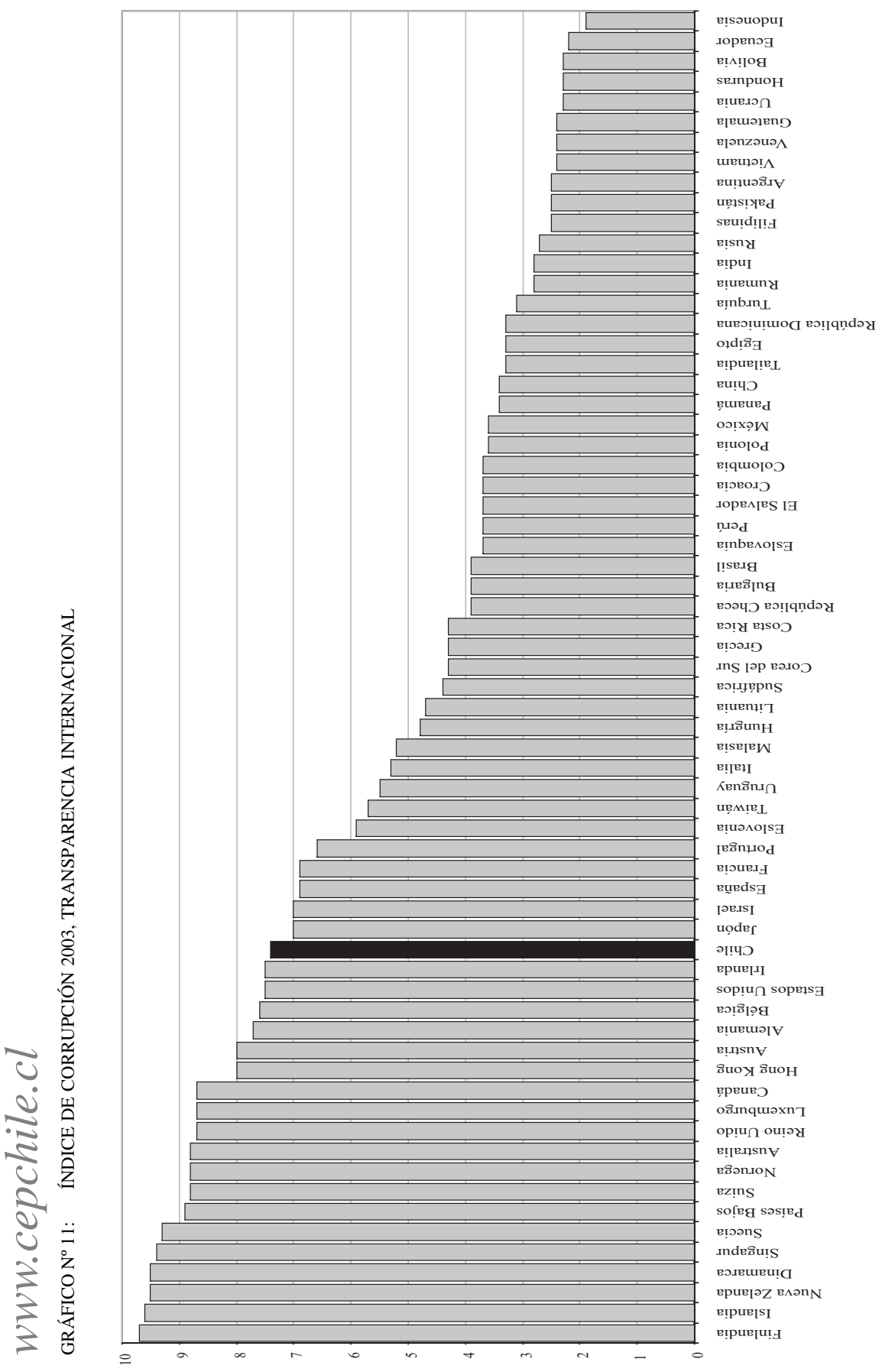


Más ampliamente, la autonomía del estado autoritario chileno y su capacidad de instalar cambios institucionales también, irónicamente, fue apoyada por varios factores que surgían directamente de la larga tradición de políticas democráticas de Chile. Sus fuerzas armadas eran únicas en el continente...

Pero no fue solo la tradición de una fuerza militar apolítica la que facilitó la implementación de dramáticas medidas de reforma. Las políticas abiertas y competitivas forjaron, a lo largo de varias generaciones, un estado relativamente fuerte y eficiente, que fomentó un respeto amplio para el estado de derecho. Aunque el régimen militar fue obligado a aplicar medidas para reducir el tamaño excesivo de agencias estatales, el alto grado de probidad, profesionalismo y experiencia en el sector público chileno, incluyendo los tribunales y muchas empresas estatales, hizo más fácil el proceso de reforma. Los chilenos obedecían las reglas creadas por las nuevas autoridades, aunque muchos cuestionaron la legitimidad de los mismos gobernantes. En contraste con la experiencia de muchos países vecinos, los esquemas de privatización y reforma fueron ejecutados con un mínimo de corrupción, los ciudadanos pagaban sus impuestos, y los actores del sector privado rápidamente aprendieron a ajustarse a las nuevas normas creadas para corregir las deficiencias de los primeros intentos por abrir la economía chilena.

De hecho, si Chile hubiese tenido instituciones débiles, poco respeto por el estado de derecho, y una corrupción descontrolada, a principios de los 70, la orientación del gobierno militar podría haber sido muy distinta. Probablemente, este episodio habría terminado de manera similar a las dictaduras corruptas en otros países de la región, con una falta de progreso en todas las áreas.

En efecto, Chile gozaba de una base institucional apropiada para la introducción de las reformas necesarias para un mercado libre y estas duraron. Sin embargo, las instituciones fuertes y un gobierno eficiente por sí solos no son suficientes para fomentar la inversión y el crecimiento. Estas instituciones también deben entregar los incentivos necesarios para la acumulación de factores y el crecimiento de la productividad. Las instituciones deben garantizar los derechos a la propiedad y quizás fue precisamente esto uno de los problemas del primer gobierno democrático que siguió a Pinochet. Hubo incertidumbre acerca de su compromiso con una economía de mercado abierto y estable, y por este motivo la reducción de las tarifas, la mantención de la responsabilidad fiscal, y las otras políticas pro-mercado de principios de los 90 fueron claves para ganar credibilidad. Los primeros años de la democracia establecieron la base para las tasas récord de inversión y el crecimiento rápido de la productividad en los 1990, después de la fase de recuperación, a fines de los 80 , se enfocaron a recuperar el empleo. 
Instituciones eficientes y fuertes garantizaron los derechos a la propiedad, promovieron una economía abierta de mercado y proporcionaron la infraestructura social necesaria para el crecimiento futuro.

En años más recientes se ha progresado significativamente en la medición de la calidad institucional. Desde el punto de vista del inversionista, es importante evaluar los riesgos y costos cuando se invierte en diferentes países. Pero desde el punto de vista de la política también es importante saber, dentro de una perspectiva comparativa, las debilidades y fortalezas principales de un país que contempla reformas de política. Desde el trabajo de Djankov et al. (2002) y del Banco Mundial sobre la regulación de los costos de entrada y de comenzar un negocio, los datos han evolucionado, llegando a constituirse en lo que es el informe Doing Business del Banco Mundial. Este informe considera siete categorías, cada una conteniendo un número de elementos distintos, con los datos para un universo de 145 países. Los indicadores se construyen sobre la base de encuestas, con preguntas estandarizadas que se dirigen a un grupo de abogados y empresarios. Los países pueden rankearse en cada categoría y puesto que informan de indicadores cualitativos de la regulación y la institucionalidad, aquí se construyen índices que representan un ranking promedio para un conjunto de indicadores. Para cada categoría se computó el ranking promedio y se construyó un nuevo ranking en cada categoría.

Chile se ubica en el puesto 36 del ranking general; el Cuadro $\mathrm{N}^{\circ} 8$ proporciona una lista de los primeros 36 países. Igual que con los otras variables presentadas aquí, Chile es el primer país de América Latina y también se ubica antes que la mayoría de los países asiáticos y muchos países industrializados. El ranking de Chile en cada categoría y subcategoría se presenta en el Cuadro $N^{\circ}$ 9. Para varios indicadores, incluyendo la facilidad con la cual se puede iniciar un negocio, inscribir una propiedad, contratar y despedir a empleados, proteger a los inversionistas y hacer valer los contratos Chile califica muy bien. Sin embargo, en términos de conseguir crédito y especialmente cerrar un negocio, no califica tan bien, particularmente en ciertas subcategorías ${ }^{27}$.

En el área del crédito, y quizás sorprendentemente a la luz de la profundidad y la fuerza del sector bancario tal como se exploró anteriormente, su desventaja principal es el costo de generar garantías (colateral). Este índice estima el costo de crear e inscribir una garantía como un porcentaje

${ }^{27}$ La razón por la cual el ranking de un país en una categoría dada podría ser peor que cualquiera de sus rankings de subcategoría tiene que ver con la distribución de los rankings y el hecho de que, para algunos ítemes, muchos países tienen el mismo ranking. 
CUADRO No 8: DOING BUSINESS, PRIMEROS 36 PAÍSES

\begin{tabular}{lccccccc}
\hline 1 & Nueva Zelanda & 10 & Japón & 19 & Bélgica & 28 & Federación Rusa \\
2 & Singapur & 11 & Singapur & 20 & Latvia & 29 & Samoa \\
3 & Estados Unidos & 12 & Suecia & 21 & Irlanda & 30 & Corea del Sur \\
4 & Noruega & 13 & Puerto Rico & 22 & Taiwán & 31 & Tonga \\
5 & Canadá & 14 & Dinamarca & 23 & Austria & 32 & Botswana \\
6 & Hong Kong & 15 & Lituania & 24 & Francia & 33 & Islas Salomón \\
7 & Australia & 16 & Países Bajos & 25 & Kiribati & 34 & Sudáfrica \\
8 & Reino Unido & 17 & Armenia & 26 & Alemania & 35 & Estonia \\
9 & Finlandia & 18 & Fiji & 27 & Tailandia & 36 & Chile \\
\hline
\end{tabular}

CUADRO No 9: $\quad$ EL RANKING DE CHILE EN CADA CATEGORÍA

\begin{tabular}{lr|lr}
\hline Creación de una empresa & 19 & Obtener un crédito & 61 \\
Número de trámites & 8 & Costo de la creación de una garantía & 33 \\
Duración & 22 & Índice de derechos legales & 7 \\
Costo & 32 & Índice de información sobre el crédito & 1 \\
Capital mínimo & 1 & & \\
& & & \\
Inscripción de propiedad & 16 & Fiscalización de contratos & 30 \\
Número de trámites & 6 & Número de trámites & 14 \\
Demora & 24 & Demora & 36 \\
Costo & 11 & Costo & 27 \\
& & & \\
Cierre de una empresa & 111 & Contrataciones y despidos & \\
Demora & 48 & Rigidez del empleo & \\
Costo & 10 & Costo del despido \\
Tasa de recuperación & 89 & & 31 \\
& & & \\
Protección a los inversionistas & 6 & & \\
Índice de transparencia & 6 & & \\
& & &
\end{tabular}

del ingreso per cápita; en el caso de Chile el costo es 5,3 veces el ingreso per cápita. Para construir este costo, se les pidió a todos los participantes evaluar el costo de crear una garantía para un negocio estándar, incluyendo los impuestos, los pagos de notaría, y las tarifas asociadas a la creación y la inscripción de la garantía. Algunos países no tienen ningún sistema de registro así que el precio puede ser bajo pero la incertidumbre que enfrentan los acreedores puede ser mayor. Otra debilidad de la institucionalidad chilena es la tasa de recuperación al cierre de una empresa. La tasa de recuperación mide cuántos centavos por dólar los acreedores típicamente rescatan de una empresa insolvente y se asocia directamente con las debilidades de 
las leyes de quiebra ${ }^{28}$. Chile ocupa el puesto 89 en este índice, con un monto recuperado que promedia 19 centavos de dólar. Los primeros 31 países todos ofrecen tasas de recuperación mayores a 50 centavos de dó$\operatorname{lar}^{29}$, lo cual ilustra la necesidad de mejorar las condiciones de quiebra en Chile y los beneficios que una mejora de esta naturaleza ofrece.

En varias otras categorías Chile se ubica en algún puesto entre $20 \mathrm{y}$ 50. Una de estas es el tiempo que se requiere para completar varios trámites, tales como inscribir una propiedad, hacer valer un contrato y cerrar una empresa. Asegurar una respuesta burocrática rápida también mejoraría el ambiente empresarial en Chile. Finalmente, el país tiene un mercado laboral relativamente flexible pero los costos de despido son relativamente altos. En efecto, en Chile el despido de un trabajador con un contrato normal requiere un mes de sueldo por cada año que el empleado ha trabajado para la empresa, hasta un máximo de 11 años. En años recientes ha habido mucho debate acerca de la flexibilidad del mercado del trabajo y su impacto en el crecimiento del país, pero una evidencia sólida es elusiva. Por ejemplo, Calderón y Chong (2003) encuentran resultados mixtos para la asociación entre la regulación del mercado de trabajo (su flexibilidad, el número de normas y la fiscalización) y el crecimiento. Sin embargo, yo creo que el tema importante, dada la ubicación actual de Chile, debe ser el alivio de la pobreza y el empleo. Por ejemplo, con algunas reformas recientes y propuestas de reformas, el tema relevante es el nivel hacia el cual la tasa de empleo convergerá en el largo plazo, y cómo los pobres y los trabajadores no calificados encontrarán empleo.

De todas maneras se puede progresar en muchos ámbitos, incluso aquellos donde el posicionamiento de Chile es relativamente pobre, y el progreso es mucho más relevante aún para el futuro, puesto que Chile tendrá que competir con países con buenas instituciones. En general, sin embargo, Chile ya cuenta con buenas instituciones y un buen ambiente para realizar negocios. Esto lo confirman muchas otras evaluaciones y rankings. Por ejemplo, el Índice de Competitividad del World Economic Forum, y el índice de Libertad Económica, del Heritage Foundation, consistentemente ubican a Chile entre los primeros de los países en desarrollo.

${ }^{28}$ Bergoeing et al. (2002) argumentan que un factor importante en la recuperación de los 80 fue la modificación de la ley de quiebras. Esto no es inconsistente con la evidencia que se ofrece aquí, puesto que las reformas de 1982 representaron un progreso importante; de todas maneras, la evidencia ofrecida aquí destaca las debilidades que siguen presentes en los trámites de quiebra y su relación con las tasas de recuperación.

${ }^{29}$ La tasa de recuperación de las primeras 15 economías (Japón, Singapur, Finlandia, Taiwán, Canadá, Irlanda, Noruega, Bélgica, los Países Bajos, el Reino Unido, Latvia, España, Hong Kong, Corea del Sur y Australia) es mayor a 80 centavos de cada dólar. 


\subsection{Infraestructura: Elevada inversión y stock aún insuficiente}

Una serie de estudios han examinado el papel de la inversión pública en la promoción del crecimiento económico. El primer trabajo importante en este ámbito fue el de Aschauer (1989), quien concluyó que el stock de infraestructura pública tiene un papel determinante en el crecimiento de la PTF. En una serie de estudios más recientes, Calderón y Servén (2004a, 2004b) han vuelto a considerar el tema con una base de datos grande y cuidadosamente construida para facilitar las comparaciones internacionales. Demuestran que la disponibilidad y calidad de la infraestructura efectivamente juegan un papel determinante en la tasa de crecimiento económico. Los variables principales que ellos han explorado son indicadores para las telecomunicaciones, la energía y los caminos. Adicionalmente, demuestran que un aumento en la dotación de infraestructura pública reduce las desigualdades del ingreso.

Se puede utilizar un gran número de variables para medir la calidad de la infraestructura disponible. Estas variables en general se correlacionan: por ejemplo, los países con una buena infraestructura de telecomunicaciones tienden a tener también una buena capacidad de generación de electricidad. Para facilitar comparaciones confiables para un análisis entre países, Calderón y Servén (2004a) construyen dos índices sintéticos, uno para la dotación de infraestructura y el otro para su calidad. Cada índice corresponde al primer componente principal de un conjunto de indicadores ${ }^{30}$. Ocuparé sus datos para presentar un resumen de la evidencia.

El índice agregado del stock de infraestructura se construye sobre la base de aproximaciones (proxies) para la infraestructura en telecomunicaciones (número de líneas telefónicas por trabajador), generación de electricidad (capacidad de generación, en gigavatios por trabajador) y caminos (largo de la red vial, normalizado utilizando el área del país). Estas tres variables se correlacionan a un nivel muy alto, entre países y el componente principal explica 81 por ciento de su variabilidad. El índice agregado de calidad de infraestructura se computa de forma similar, utilizando los siguientes indicadores: la demora para obtener una línea telefónica, las pérdidas en la transmisión y distribución del total de energía eléctrica generada, y los caminos pavimentados como porcentaje de la red vial total.

El Gráfico No 12 muestra estos índices de disponibilidad y calidad de la infraestructura para Chile desde 1971. El gráfico también muestra los pro-

${ }^{30}$ Para simplificar, dado un conjunto de variables correlacionadas, el análisis de componentes principales transforma los datos en otro conjunto de variables sin correlación, donde el primer componente principal es el que explica la mayoría de la variabilidad en los datos. 
GRÁFICO N ${ }^{\circ}$ 12: $\quad$ STOCK Y CALIDAD DE LA INFRAESTRUCTURA

(a) Stock

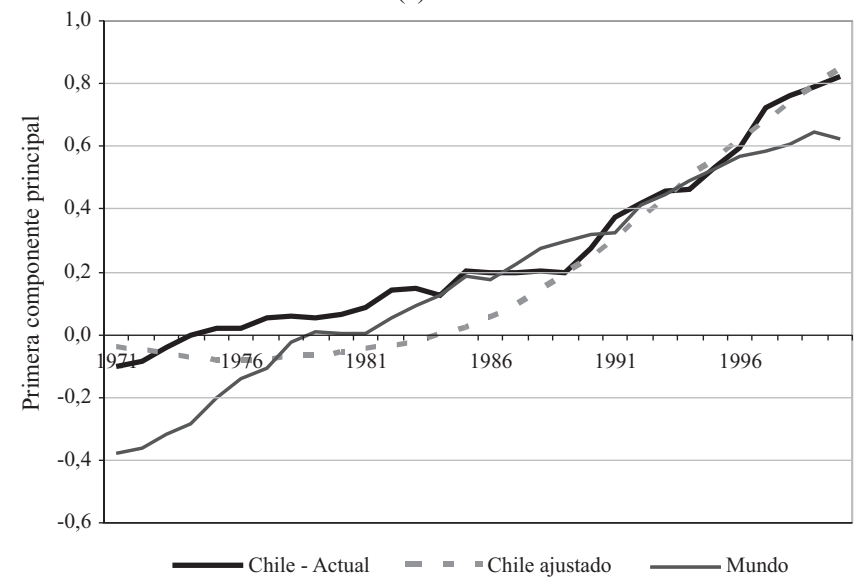

(b) Calidad

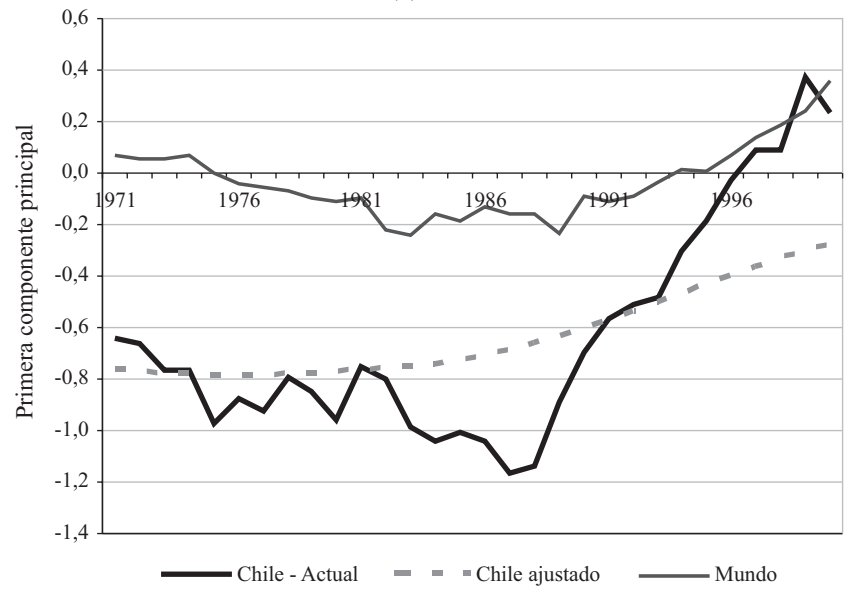

medios mundiales para estos dos indicadores y los valores esperados para Chile, dado su nivel de ingreso (línea Chile-ajustado). Los valores esperados son filtrados utilizando el filtro Hodrick-Prescott para eliminar las influencias del ciclo económico. El crecimiento de infraestructura disponible en Chile fue muy lento durante los 70 y especialmente en los 80 , pero mucho más rápido de lo que se habría previsto dada la baja tasa de crecimiento del país. El stock de infraestructura aumentó permanentemente durante los 90, a una tasa más rápida que la del mundo como un todo. De todas maneras el 
progreso más impresionante se ve en términos de su calidad. Después de una caída en la calidad de la infraestructura durante los 80 , en el mundo y más drásticamente en Chile, las mejoras en Chile fueron destacables.

¿Fue la inversión pública la responsable del despegue de mediados de los 80 ? Aunque la inversión pública no puede explicar la recuperación de fines de los 80 (que como se discutió en el contexto de las descomposiciones de crecimiento en un principio tienen poco que ver con la inversión), sí fue factor clave de apoyo al crecimiento en los 90. Primero, el crecimiento en la inversión pública siguió una trayectoria paralela a la del producto, así que no se convirtió en un cuello de botella para el crecimiento. Adicionalmente, la mejora impresionante en la calidad tiene que haber impactado significativamente en el crecimiento de la PTF. Finalmente, la inversión en infraestructura fue un portador relevante de la inversión extranjera directa, que a su vez tuvo repercusiones importantes en el crecimiento durante los 90. Sin embargo, cabe aclarar que la inversión en infraestructura ayuda a explicar la persistencia del despegue de los 90, sin embargo la infraestructura disponible sigue siendo insuficiente, como se explica a continuación.

Por lo tanto, Chile ha experimentado una mejora notable en su infraestructura a través del tiempo. ¿Pero cómo son estos resultados desde una perspectiva internacional? Para responder esta pregunta, comparo los índices sintéticos de cantidad y calidad de infraestructura para Chile en 2000, los últimos años con datos disponibles, con los de aquellos países para los cuales los datos están disponibles para el mismo año. La comparación se hace con y sin ajuste para el nivel de ingreso, para una muestra de unos 100 países, cuyo número exacto depende del indicador de que se trate. En esta comparación, Chile ocupa el puesto 48 en el indicador de cantidad bruto, y 49 cuando se ajustan los datos para el ingreso. Por lo tanto, la infraestructura disponible en Chile se acerca al promedio mundial ${ }^{31}$. Se obtienen rankings similares cuando se compara la calidad: cuando se ajustan los datos por el ingreso, Chile ocupa el puesto 57.

En resumen, la evidencia indica que la década de los 90 mostró una expansión extraordinaria en la infraestructura en Chile. Este crecimiento involucró no solo la inversión pública, sino también una participación sustancial del sector privado, que fomentó la inversión extranjera directa. Además, este auge en la inversión, no solo cimentó el potencial de crecimiento de Chile de largo plazo, sino que también le imprimió un impulso de corto plazo

31 Para una comparación más precisa, uno quisiera controlar otras características del país, tales como rasgos geográficos. Esto no se hace aquí, pero para una comparación internacional más comprensiva, véase Calderón y Servén (2004b), que confirma estas observaciones en el texto. 
a la actividad. Desde una perspectiva internacional, este esfuerzo ayudó a Chile a alcanzar el promedio mundial después de un largo período de atraso en infraestructura. No obstante, la comparación internacional también revela, que aún queda una brecha entre Chile y los países en desarrollo más avanzados, como las economías del Este de Asia, en términos de disponibilidad y calidad de la infraestructura. Por este motivo, el repunte de la inversión fue una fortaleza de los 90, pero la disponibilidad aún puede mejorarse.

\section{Crecimiento de largo plazo: Debilidades}

Ya se han visto algunos de los factores institucionales que podrían limitar el crecimiento en Chile, tales como el bajo nivel de activos que se recuperan cuando quiebra una empresa y el alto costo para constituir garantías, o el progreso que aún resta en materia de infraestructura. En esta sección, sin embargo, señalaré otras áreas más generales que pueden limitar el crecimiento futuro ${ }^{32}$. Al igual que en la sección anterior, la selección de áreas no están basadas en evidencia particular, sino más bien en una revisión amplia de la evidencia de años recientes.

\subsection{Investigación y desarrollo}

Los países que dedican un mayor porcentaje del PIB que otros a la investigación y el desarrollo (ID) tienden a crecer más rápidamente (Lederman y Maloney, 2003). La ID permite a los países adoptar mejores tecnologías y proporciona nuevos y mejores bienes, y los frutos de esta actividad se difunden al resto de la economía. El Gráfico $\mathrm{N}^{\circ} 13$ ofrece una visión inicial de los datos, mostrando el gasto en ID como porcentaje del PIB de Chile y varios grupos de países seleccionados. Chile siempre ha gastado relativamente poco en ID, y el aumento desde 1980 ha sido magro comparado con los países del Este de Asia, e incluso comparado con el promedio mundial. Los datos más recientes de la OCDE muestran que Chile, con un gasto en ID que llega a 0,54 por ciento del PIB gasta menos que el promedio de una muestra de países en desarrollo ( 0,7 por ciento del PIB $)^{33}$. Lederman y Sáenz (2003) confirman esta conclusión.

32 En el Ministerio de Hacienda (2004) hay una discusión útil y detallada sobre dos temas que cubro en esta sección: I\&D y la calidad de la educación.

33 Para no sobre-representar a los países con un gasto muy alto en I\&D, excluyo los que más gastan de Asia y Europa, más Brasil, que gasta aproximadamente uno por ciento del PIB en ID. Para mayores detalles, véase OCDE (2003). 
GRÁFICO N 13: GASTO EN INVESTIGACIÓN Y DESARROLLO (\% DEL PIB)

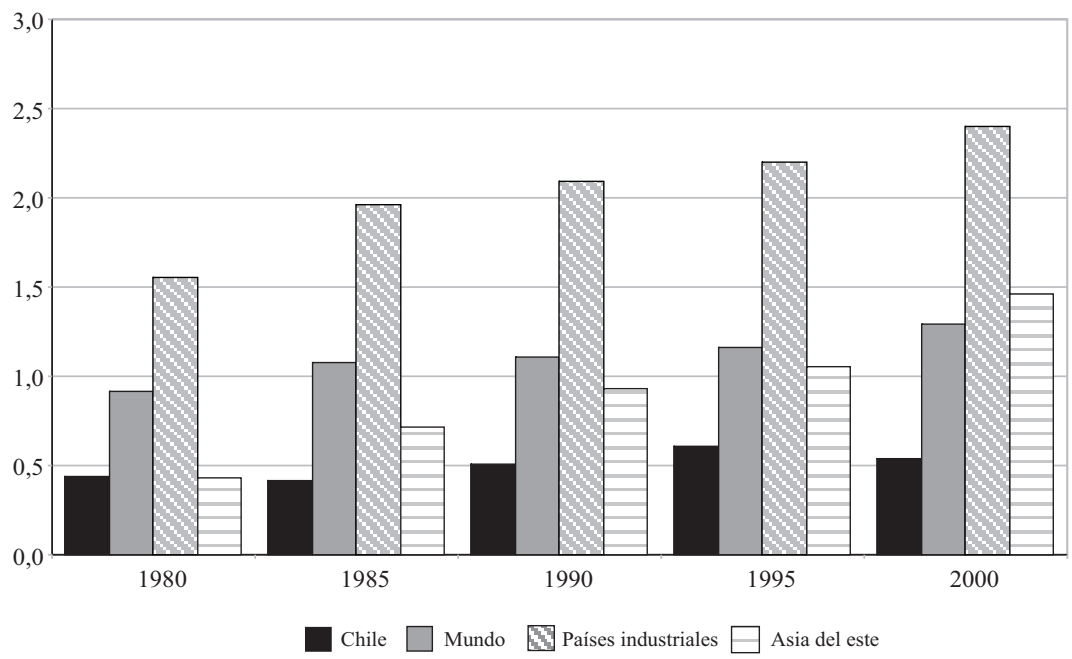

GRÁFICO No 14: I\&D GASTO E INGRESO, 1995

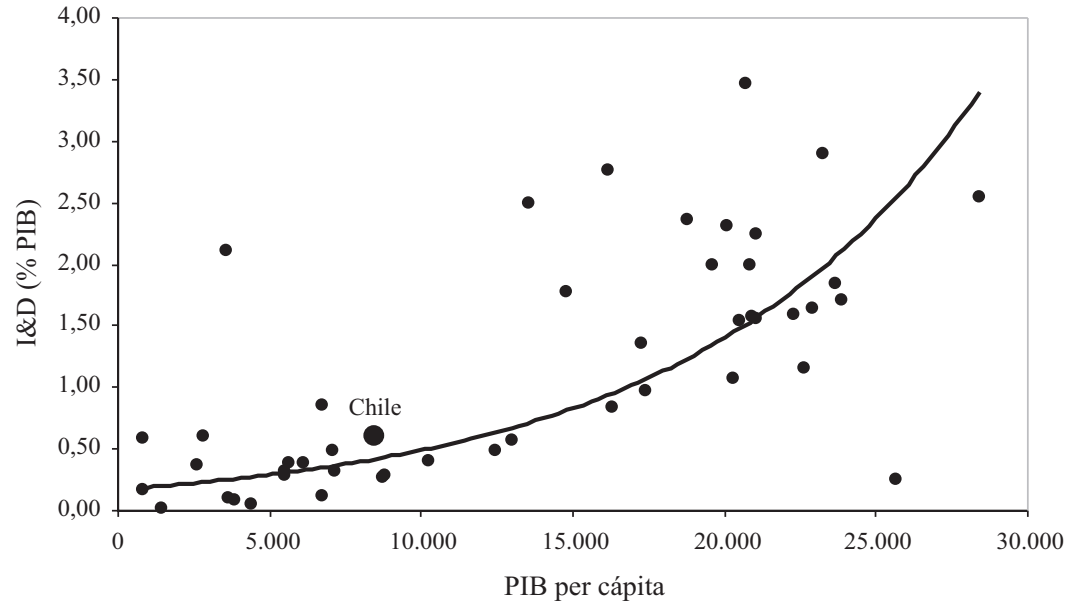

Claramente, sin embargo, hay un efecto ingreso. Se esperaría que, en la medida que una economía se hace más rica y con una mayor dotación de 3 capital humano podrá gastar más en la ID. El Gráfico No 14 muestra que 3 cuando se ajusta el gasto en ID sobre el PIB para el ingreso del país, el nivel 
de ID de Chile se acerca a lo esperable para su ingreso. (Los datos del Gráfico No 14 son de 1995, porque no hay disponibles cifras más recientes para muchos países, pero los resultados son casi los mismos para una muestra mucho más pequeña de 2000.) No obstante, un aumento en el gasto en ID sin duda ayudaría al país a crecer más rápidamente. En efecto, según Lederman y Maloney (2003), al aumentar el gasto en ID en medio punto porcentual del PIB, aumentaría el crecimiento del PIB en 0,3 o 0,4 puntos porcentuales anuales.

La composición de la ID en Chile es muy diferente a lo típico en el resto del mundo, surgiendo la pregunta acerca de su eficiencia. El 2000, aproximadamente un 55 por ciento del gasto chileno en ID se invirtió en ciencias básicas, en vez de investigación aplicada. En los países industrializados y del Este de Asia, esta participación normalmente se ubica entre 10 y 20 por ciento. No existen motivos para creer que la ciencia básica podría favorecer más el crecimiento que la investigación aplicada en Chile; en efecto, la suposición sería la opuesta.

El Gráfico N ${ }^{\circ} 15$ ofrece una desagregación sectorial del gasto en ID de Chile y otros países en desarrollo e industrializados. La participación del gasto ID es relativamente baja en Chile, solo 26 por ciento comparada con el promedio de $70 \%$ en los países de la $\mathrm{OCDE}^{34}$. En el otro extremo, y consistente con los datos sobre la participación de la ciencia básica en la investigación, Chile se ubica en el quinto lugar en cuanto a participación del gasto en ID por instituciones de educación superior: esa participación es de 45 por ciento del total, o el doble del promedio mundial. El gasto gubernamental, en 29 por ciento del total, es algo más que la media mundial de 22 por ciento. La lección para la política es clara. Chile debe tratar de aumentar su gasto en ID y el gasto debería dedicarse principalmente a la ID aplicada, ejecutada por el sector privado $^{35}$.

\subsection{Desigualdad y distorsiones de la política}

La teoría y la evidencia empírica sugieren que una distribución desigual del ingreso es mala para el crecimiento, aunque hay algo de evidencia reciente que cuestiona esa perspectiva. En vez de tratar de resolver este

${ }^{34}$ Sin embargo, las cifras para los países OCDE podrían estar algo sobredimensionadas, puesto que muchos países subsidian la ID, que incentiva declarar mayor gasto en ID.

35 Cómo las empresas invierten en ID también es relevante. Por ejemplo, la licencia puede ser un mecanismo barato y efectivo para adquirir una tecnología. Álvarez et al. (2002) han demostrado que, en el caso de Chile, el rendimiento de un sistema de patentes puede ser el doble que el de una inversión en capital físico. 


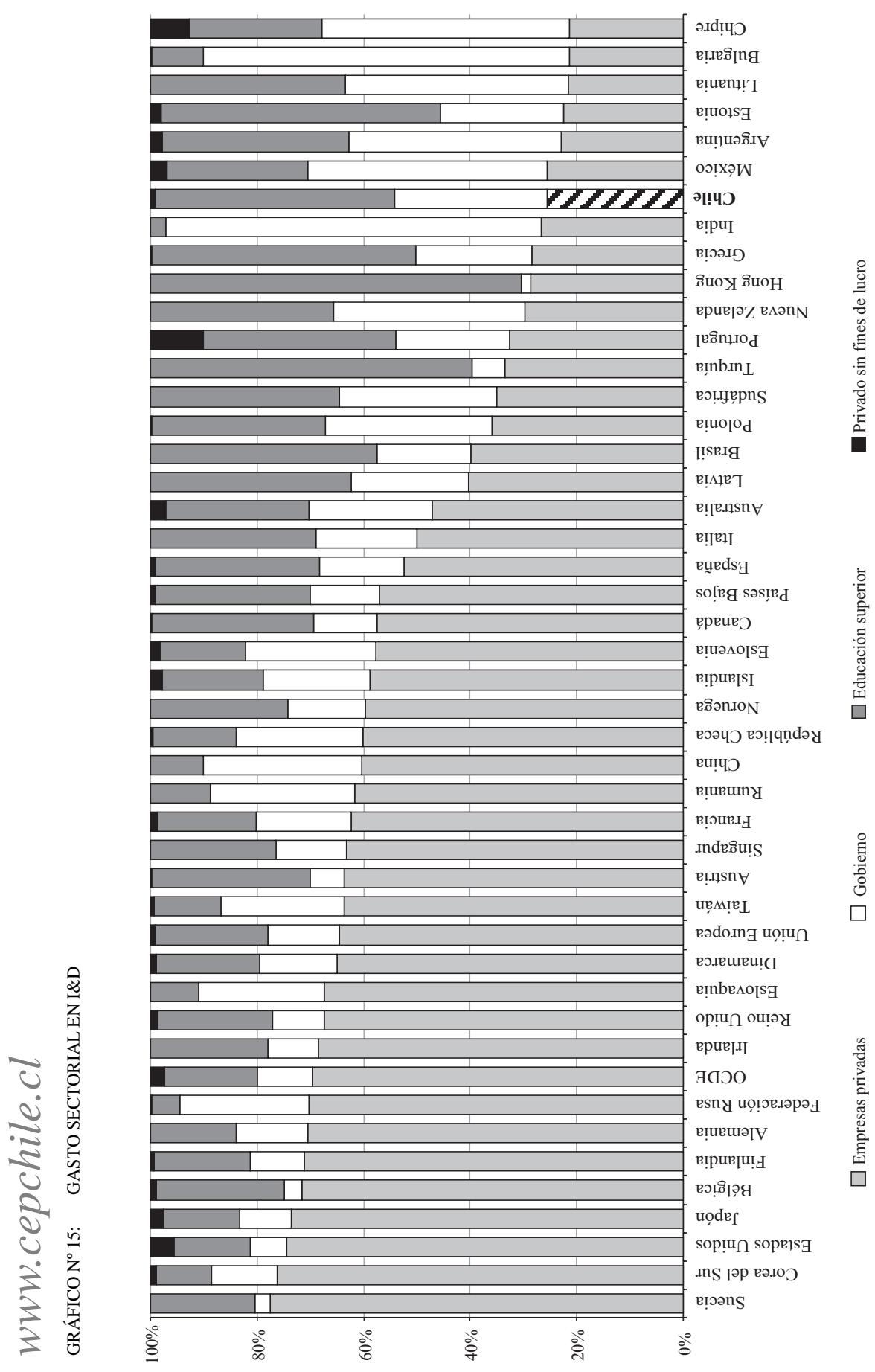


debate aquí, puede que sea más fructífero explorar los mecanismos específicos a través de los cuales la desigualdad podría afectar el crecimiento. En efecto, la literatura teórica enfatiza que la desigualdad puede llevar a políticas ineficientes que llegan a dañar el crecimiento, en su esfuerzo por corregir esa inequidad. El caso clásico es la introducción de un sistema de impuestos ineficientes para propósitos redistributivos.

En De Gregorio y Lee (2004) se concluye que, después de ajustar por el nivel de desarrollo, los países con una distribución del ingreso más desigual, medido por el coeficiente de Gini (mientras mayor es su valor mayor es la desigualdad), son más propensos a tener condiciones y políticas económicas nocivas para el crecimiento. Por ejemplo, tienen tasas menores de escolaridad, probablemente porque después de controlar por el ingreso promedio quedan con una fracción mayor de población incapaz de costear sus estudios. También encontramos que los países con mayor desigualdad tienen mayores tasas de fertilidad, gobiernos más grandes, menores logros educativos e instituciones más débiles.

Aunque los que deciden las políticas en general prefieren las que simultáneamente elevan el crecimiento y reducen la desigualdad, esto no siempre es posible. Algunos prefieren adoptar políticas redistributivas que introducen distorsiones y dejan de adoptar otras políticas, como la educación universal para los pobres, que podrían influir positivamente en el crecimiento y la desigualdad. Puesto que los pobres tendrán menos incentivo para adquirir educación, una política que activamente fomenta la educación será buena tanto para el crecimiento como para la reducción de la desigualdad.

Lo que se hace aquí es comparar las predicciones para una variable dada que afecta el crecimiento, después de ajustar por el nivel de ingreso, con el nivel actual de esta variable para Chile, comparado con el nivel de desigualdad. Esto es similar al ejercicio anterior que comparaba el tamaño del gobierno chileno con lo que se esperaría para su nivel de ingreso. Las cuatro variables que se analizan son las examinadas en De Gregorio y Lee (2004): la educación (medida por la tasa de matrícula), la fertilidad, el tamaño del gobierno (medido por el gasto gubernamental en bienes y servicios), y la calidad de las instituciones (medida por un índice de respeto del estado de derecho).

El Gráfico N 16 presenta los resultados de esta comparación. El primer punto que hay que destacar es que Chile tiene una distribución de ingreso relativamente desigual según el coeficiente de Gini. En efecto, el Gini de Chile está entre los altos del mundo. El panel superior del lado izquierdo del gráfico compara la desigualdad con la matrícula en la educa- 

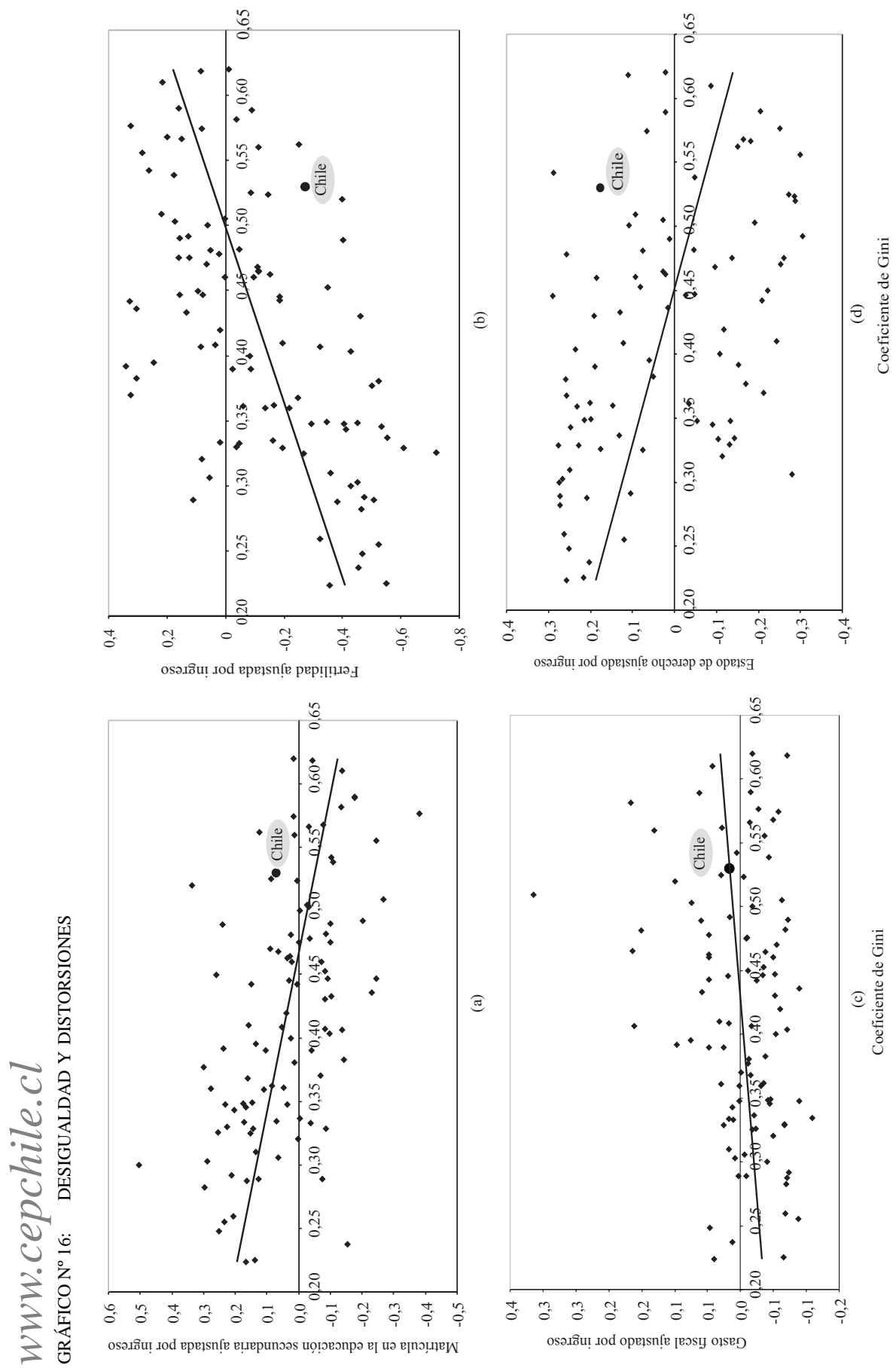
ción secundaria y revela una relación negativa. Después de ajustar por el ingreso, sin embargo, la matrícula al nivel secundario en Chile es mayor al que se esperaría dada la alta desigualdad (se ilustra con la línea recta). Esto indica el rol positivo de las políticas educacionales, que han incrementado la matrícula más allá de lo que se esperaría para el nivel de ingreso de Chile.

Se observa un patrón similar para la fertilidad, según el panel superior derecho. Se sabe que una tasa de fertilidad más alta produce una tasa de crecimiento del ingreso per cápita menor, y el gráfico demuestra la relación positiva entre tasas de fertilidad y desigualdad. Nuevamente, sin embargo, una vez ajustada por el ingreso, la tasa de fertilidad de Chile es menor a la esperada dado su nivel de desigualdad. Muchos factores son responsables, particularmente la salud y la educación.

La relación entre el tamaño del gobierno y la desigualdad, que se ve en el panel izquierdo inferior es algo más débil ${ }^{36}$, y en este caso Chile aparentemente cae exactamente en el nivel esperable para esta relación. Finalmente, el panel inferior derecho muestra que, para un nivel dado de ingreso, los países con mayores desigualdades tienen instituciones más débiles: el respeto por el estado de derecho baja mientras sube la inequidad (se obtienen resultados similares para otros indicadores, por ejemplo la corrupción). Para este indicador, sin embargo, los puntajes de Chile son bastante mayores a lo que se esperaría con su nivel de desigualdad. Al ajustar por el ingreso, el respeto por el estado de derecho en Chile se aproxima al nivel que se observa en los países con muy bajos niveles de desigualdad.

En general, aunque Chile tiene un alto nivel de desigualdad, la evidencia que se documenta aquí demuestra que en general ha logrado evitar las distorsiones que a menudo dificultan el crecimiento en países con niveles similares de desigualdad. Por supuesto, esto se ha demostrado sólo para un conjunto limitado de factores para los cuales contamos con evidencia empírica internacional. Sin embargo, otras experiencias revelan que el "trade-off” entre la eficiencia y la desigualdad está siempre presente en la política pública y no puede evitarse. Un ejemplo es el salario mínimo.

Desde los principios de los 90, en un esfuerzo por mejorar las condiciones de vida de los pobres, Chile ha legislado aumentos significativos en el salario mínimo. Durante la primera parte de la década, el producto, la productividad y los salarios crecían con fuerza, y así no se notaba el efecto

${ }^{36}$ Aunque la estrategia que se emplea aquí es muy sencilla, parece que la relación verdadera entre el gasto fiscal y la inequidad no es lineal y depende del nivel de ingreso, especialmente dado que, al contrario de lo que dice el argumento acerca de las políticas distributivas, la inequidad y el tamaño del gobierno se correlacionan negativamente en los países de la OCDE. 
del aumento del salario mínimo en el empleo. En 1998, sin embargo, justo en el momento en que la economía iniciaba su desaceleración, se implementó un aumento adicional del salario mínimo, de considerable magnitud: además, por primera vez se estableció el salario mínimo para tres años, con aumentos de alrededor de $10 \%$ al año. Anteriormente, el salario mínimo se establecía todos los años mediante un tedioso proceso de negociación, y por este motivo la idea de un acuerdo de largo plazo parecía atractiva. Pero no se tomó ninguna provisión para las contingencias y, con la economía experimentando una desaceleración, el salario mínimo comenzó a crecer más rápidamente que el salario promedio para los trabajadores no calificados. Hacia mediados de 1998, el salario mínimo llegaba a 45 por ciento del salario promedio de los trabajadores no calificados y a mediados de 2000 la razón llegaba a 60 por ciento. Y esto ocurrió precisamente en el momento en que la economía más necesitaba la moderación de los salarios. El salario mínimo más alto demostró ser una causa importante en la desaceleración del crecimiento en el empleo en años recientes, fenómeno que fue mayor entre los trabajadores no calificados (Cowan et al., 2003).

Finalmente, el propio crecimiento ayuda a la implementación de buenas políticas. La desigualdad es solo un aspecto de las condiciones de vida de un país y en un país con una distribución del ingreso que permanecía relativamente sin cambio entre 1987 y 2003, un período en el cual el ingreso per cápita se dobla también duplica los ingresos de los pobres. En efecto, la tasa de pobreza en Chile cayó durante este período desde 45 por ciento hasta 19 por ciento de la población. Esto permitió a la política pública enfocar la tarea de aliviar la pobreza sin crear distorsiones significativas en el crecimiento económico. Aunque la distribución del ingreso de un país cambia lentamente y no hay receta disponible para un cambio dramático en la distribución (salvo una redistribución populista y masiva, que no es aconsejable), el crecimiento puede reducir las distorsiones impuestas por la desigualdad en las políticas e instituciones.

\subsection{Calidad de la educación}

Chile goza de altos niveles de escolaridad y el progreso a lo largo de las décadas ha sido muy alentador. Actualmente, el nivel de educación de la fuerza de trabajo chilena es coherente con el nivel de ingreso del país. Sin embargo, hay evidencia de que la calidad de la educación no es tan buena como podrían sugerir las altas tasas de matrícula ${ }^{37}$.

37 Para más sobre los niveles y la calidad de la educación, véase Tokman (2004). 
Chile participó en una encuesta internacional de la alfabetización adulta (Adult Literacy Survey, IALS), que buscó medir directamente la calidad de la población en la edad de trabajar de un país, más que sus estudiantes. Resulta que Chile, que era el único participante de América Latina (además de los países de alto ingreso, sólo Chile y un par de países europeos de ingreso medio participaron), tuvo el peor rendimiento. Esto, por supuesto, refleja las diferencias de ingreso y en efecto los peores resultados eran de los países con el más bajo ingreso por habitante. Sin embargo, hay evidencia de que incluso una vez ajustado para el ingreso, Chile igualmente se comporta pobremente. Chile también participó en el tercer estudio internacional de matemática y ciencia (Third International Mathematics and Science Study, TIMSS) en 1999. Para ambas pruebas el puntaje de Chile se ubicó en el quintil más bajo. Según Barro (1999), el puntaje de Chile para la ciencia fue de 24 por ciento, comparado con un promedio para la muestra de 46 por ciento. Dado el nivel de ingreso de Chile, este puntaje debería haber alcanzado a 43 por ciento.

Otros resultados de la calidad los entrega un programa de evaluación escolar internacional de la OCDE (Programme for International Student Assessment). Este programa administra una prueba de comprensión de lectura a estudiantes de 15 años. El Gráfico $N^{\circ} 17$ presenta los resultados de la prueba para cada país contra su gasto en educación y dibuja una línea de tendencia logarítmica a través de los datos. El gráfico demuestra que, dado su nivel de gasto en la educación, el rendimiento de Chile fue bajo. Aunque estos resultados pobres sugieren que la calidad de la educación es baja, podrían deberse a otros factores. Villafuerte (2004) muestra que los niveles de escolaridad de Chile son consistentes con su nivel de ingresos, aunque los resultados TIMSS son bajos. También muestra que los malos resultados en materia de calidad están muy relacionados a los elevados niveles de desigualdad de ingresos.

En resumen, está claro que la calidad de la educación en Chile es baja, pero esto puede ser el resultado o de un gasto ineficiente en la educación o de una alta desigualdad en el ingreso, o una combinación de los dos. Es necesario investigar más para separar estos efectos. Las estimaciones sugieren que un aumento en la calidad de la educación puede ofrecer un estímulo al crecimiento económico bastante importante. Barro (1999) estima que si Chile elevara su calidad promedio de educación hasta el nivel que le correspondería de acuerdo a su nivel de ingreso per cápita, el crecimiento ganaría dos puntos porcentuales; aunque Barro también destaca que una estimación tan alta es poco plausible, de todas maneras ilustra los beneficios potenciales de un aumento en la calidad de la educación. 
GRÁFICO N 17: EFICIENCIA DEL GASTO EN EDUCACIÓN

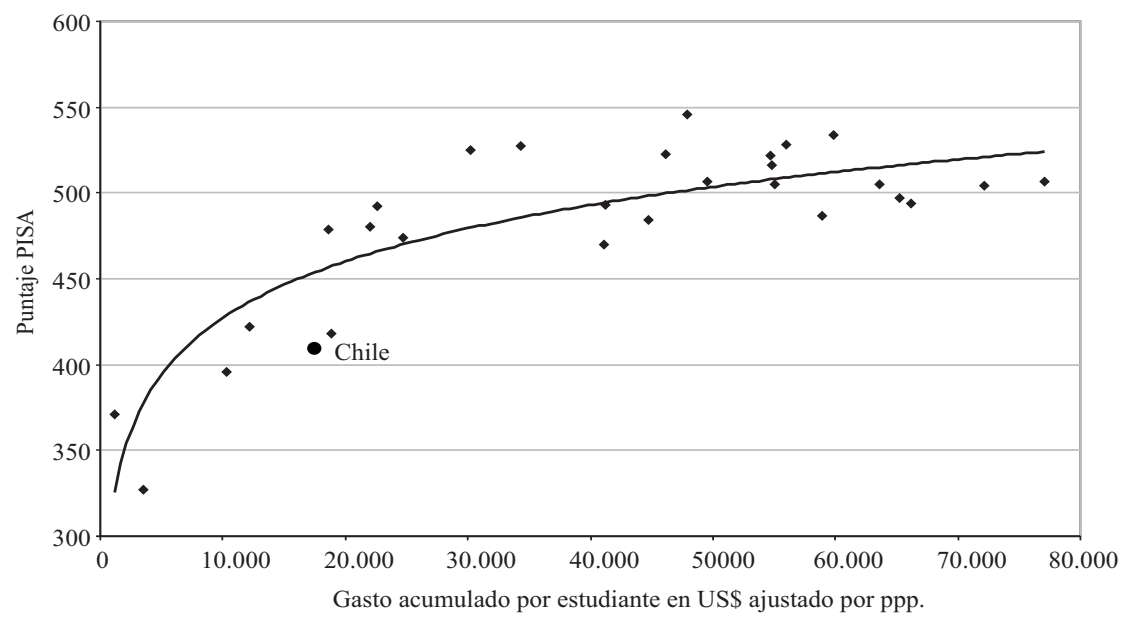

Finalmente, es importante señalar que los beneficios de mejorar la calidad de la educación demoran en la entrega de resultados significativos. Los niños que hoy podrían recibir una buena educación serán una proporción mayor de la fuerza de trabajo en unos 20 años más. El impacto de la educación en la distribución del ingreso sufre del mismo atraso. Por esta razón es importante también buscar mejorar las capacidades de las personas ya en la fuerza del trabajo a través de programas de entrenamiento. Sin embargo, a pesar de estos atrasos en los efectos de la educación, mejorar su calidad es una herramienta poderosa para igualar las oportunidades e integrar las familias pobres a los beneficios del progreso económico.

\subsection{Comercio regional}

Los primeros socios comerciales que un país debe tener son sus vecinos. La distancia, el idioma, y la cultura deberían ser la base de la integración en la economía mundial. Incluso cuando las economías vecinas tienen estructuras similares, el comercio intra-industria puede ayudar a aumentar la base del comercio. Lamentablemente, el comercio intrarregional de América Latina es bajo, como se ve en el Gráfico № 18 . El gráfico, que ocupa datos de las Naciones Unidas de dirección del comercio, muestra la participación del comercio intrarregional para varios grupos de países importantes. 
GRÁFICO No 18: EL COMERCIO INTRARREGIONAL

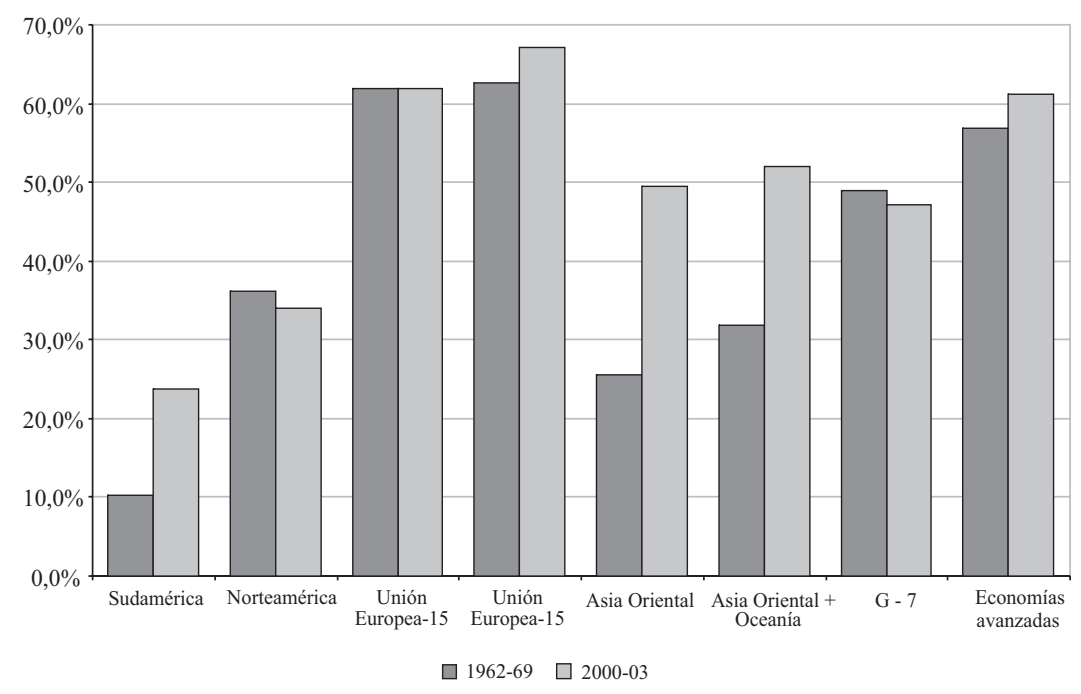

Fuente: Naciones Unidas: Comtrade Database.

El comercio intrarregional en América Latina ya estaba bajo en los 60, alcanzando aproximadamente a 10 por ciento del total, y aunque ha aumentado en años recientes sigue siendo relativamente bajo. El comercio entre los países sudamericanos es 24 por ciento de su comercio total, mientras que entre los países de América Latina es 17 por ciento, el más bajo entre las regiones del gráfico. Este mismo patrón de baja integración emerge para otras agrupaciones de países, como Mercosur o Aladi (no incluidos). Estas conclusiones contrastan fuertemente con la dinámica de comercio intrarregional entre los países del Este de Asia: ya en los 60, 26 por ciento de su comercio era entre ellos, y esa cifra se ha incrementado a 50 por ciento en años recientes. Durante mucho tiempo el comercio entre los países industrializados ha dado cuenta de una alta participación de su comercio total.

Existen razones estructurales o de índole geográfica que podrían explicar el bajo nivel comercial entre los países latinoamericanos. Por ejemplo, la apertura de un país muy grande del Este de Asia, como China, puede explicar mucho del alza en el comercio intrarregional de esa región. Latinoamérica también tiene un país que podría convertirse en un promotor importante del comercio regional, pero Brasil aun no juega ese papel. 
No obstante, América Latina es una región donde faltan los incentivos para el comercio. Ha habido muchos intentos de integración, incluyendo el Pacto Andino, Aladi, y más recientemente Mercosur, y el comercio intrarregional ha aumentado modestamente desde los 60. Pero es difícil argumentar que este aumento ha sido el resultado de estos arreglos más que un reflejo de la tendencia creciente del comercio mundial. Los acuerdos regionales formales pueden ayudar, pero están lejos de ser un estímulo suficiente al comercio intrarregional.

Desde mi punto de vista, las instituciones juegan un papel clave en el fomento del comercio. Para que los países desarrollen relaciones comerciales profundas y extensivas, cada uno debe demostrar a nivel local la capacidad de hacer cumplir los contratos, respetar el estado de derecho, y establecer relaciones comerciales duraderas. La existencia de un ambiente macroeconómico estable también es importante, porque reduce la incertidumbre entre los participantes del comercio. Sin embargo, Latinoamérica tiene instituciones débiles y recurrentes crisis macroeconómicas, y esto impide el crecimiento de relaciones comerciales. Disputas comerciales recientes - algunas de las cuales, como el problema del gas natural con Argentina y Bolivia, afectaron la economía chilena - son evidencia de estos obstáculos. Entonces, el comercio intrarregional bajo no es el problema de fondo, pero sí refleja un ambiente institucional débil para sustentar altos niveles de comercio en la región. Una región más dinámica sin duda ayudaría a estimular el crecimiento.

\section{Perspectivas de crecimiento}

Utilizando distintas metodologías, muchos estudios e informes han intentado prever el crecimiento de largo plazo para la economía chilena. Una muestra de estos estudios se resume en el Cuadro $\mathrm{N}^{\circ} 10$. Los diferentes estudios ocupan básicamente tres métodos. El primero se basa en la contabilidad del crecimiento tradicional, como aquella presentada en la sección 2.3. En este caso, la predicción se basó en ciertos supuestos: alguna estimación de la expansión del trabajo, alguna tasa de inversión de la cual se deriva la tasa de crecimiento del capital, y finalmente alguna trayectoria para la PTF. Un segundo método consiste en el uso de técnicas de series de tiempo, como el popular filtro Hodrick-Prescott u otro método más sofisticado. A veces se ocupa esta estrategia de filtración con la contabilidad del crecimiento para suavizar la acumulación de factores y el crecimiento de la PTF. Finalmente, los resultados de las estimaciones de regresiones entre 
CUADRO No 10: PREDICCIONES DE CRECIMIENTO

\begin{tabular}{lccc}
\hline Fuente & $\begin{array}{c}\text { Proyección } \\
\text { (\% por año) }\end{array}$ & Período & Método \\
& & & \\
Barro (1999) & 4,7 & $1996-2006$ & CCR \\
De Gregorio y Lee (1999) & 5,4 & $1995-2005$ & CCR \\
Coeymans (1999)* & 4,7 & $2001-2008$ & GA \\
Gallego y Johnson (2001) & 5,0 & 2000 & TS y GA \\
Hviding (2001) & 5,5 & $2001-2010$ & TS y GA \\
De la Cuadra (2002) & 4,0 & largo plazo & \\
Gallego y Loayza (2002) & 5,3 & $2001-2010$ & CCR \\
Loayza et al. (2002) & 5,7 & $2000-2010$ & CCR \\
Consensus Forecast (2003) & 4,8 & $2004-2013$ & Survey \\
De Gregorio y Lee (2004) & 4,7 & $2000-2010$ & CCR \\
Promedio & 5,0 & & \\
\hline
\end{tabular}

CCR: regresiones entre países. TS: series de tiempo.

GA: contabilidad del crecimiento.

Cuando un estudio ofrece más que una estimación se ha tomado un promedio.

* Estimaciones que consideran 1,5\% del trabajo y 2\% de crecimiento de la PTF.

países, donde se pueden hacer algunos supuestos para predecir los determinantes del crecimiento. Adicionalmente, el cuadro presenta las estimaciones de Consensus Forecasts (2003), que se basan en las encuestas que exploran las opiniones de los analistas.

Varios de los estudios resumidos en el Cuadro $\mathrm{N}^{\circ} 10$ predicen el PIB per cápita; para convertir esto al PIB, agregué un 1,7 por ciento, que es la tasa promedio de crecimiento de la población de 15 años y más en años recientes en Chile. La estimación más alta es la de Loayza y otros (2002), de 5,7 por ciento al año, y la más baja es la De la Cuadra (2002), de 4,0 por ciento; todos los otros valores se ubican entre 4,5 y 5,4 por ciento. El promedio de las estimaciones es 5,0 por ciento. Esta es la misma cifra que se presentó en la sección 2.3, como una predicción del crecimiento de largo plazo basada en una tasa de crecimiento de la productividad de 2,0 por ciento en el estado de equilibrio del modelo neoclásico de crecimiento.

Una tasa de crecimiento de 5,0 por ciento sería, por supuesto, menor al de la época dorada, y de lo que parecería ser la tasa de crecimiento deseable para Chile, de 6,0 a 7,0 por ciento, de lo que se lee en la prensa. Pero, considerando todas las fortalezas y debilidades de Chile, esta parece ser una predicción razonable. La tasa implícita de crecimiento del PIB per cápita, de 3,3 por ciento, es mayor a la que se observó durante todo el siglo $\mathrm{XX}$ en cualquier país del mundo, aunque por debajo del crecimiento en 
algunos períodos "milagrosos", como la época dorada en Chile. Para un horizonte mayor, sería una tasa de crecimiento muy saludable, de hecho más que duplica lo que el propio Chile experimentó en todo el siglo XX. El crecimiento de 3,3 por ciento anual durante 30 años aumentaría el ingreso per cápita en 165 por ciento, mientras una tasa de crecimiento de 1,7 por ciento al año lo aumentaría sólo en 65 por ciento.

Sin embargo, se deben tomar en cuenta dos precauciones al considerar estas predicciones. La primera es que el éxito del pasado ha reducido la brecha de ingreso entre Chile y los países más ricos, así que el efecto de convergencia será negativo. Esto se refiere al hecho de que los países más ricos crecen más lentamente, puesto que la productividad marginal del capital baja en la medida que sube el ingreso. Chile es mucho más rico hoy que en 1985, y por lo tanto la tasa potencial de crecimiento debería ser más baja de lo que fue entonces, todo lo demás constante. La segunda y más importante precaución es que cualquier regresión entre países subestimaría el crecimiento de Chile durante la época dorada. Esto implica que no hay cómo contabilizar toda la alta tasa de crecimiento que se logró durante ese período. Por ejemplo, el estudio más comprensivo que examina este período con regresiones de crecimiento, de Gallego y Loayza (2002), no puede explicar el despegue chileno completamente. En efecto, sus regresiones bases explican menos que la mitad del aumento en la tasa de crecimiento desde mediados de los 80. En una regresión expandida, que utiliza variables adicionales y términos de interacción, pueden reducir el error de predicción, pero de todas maneras explican sólo tres cuartos del aumento. Como se esperaba, existen factores que no se incluyen en las regresiones de crecimiento que ayudarían a explicar estos momentos de crecimiento intenso. Los estudios que incluyen más países corroboran esto. Barro y Sala-i-Martin (1995) muestran para países que se predicen tasas de crecimiento per cápita nula, terminan con un crecimiento negativo de 1\%. En el otro extremo, para algunos países de alto crecimiento se ha predicho que crecerían a una tasa de 3,9 por ciento y sin embargo logran crecer a 4,8 por ciento. Así los errores de un punto porcentual son comunes en las experiencias de crecimiento más extremas.

En el caso de Chile, el hecho de que las regresiones entre países no pueden explicar totalmente el período dorado muestra las limitaciones de enfocar un solo conjunto de regresiones con un conjunto limitado de regresores. Sin embargo, una proyección neutral de estos factores desconocidos los dejaría igual a cero. En un escenario optimista, Chile podría crecer permanentemente en un punto porcentual más rápido que la predicción, como la evidencia demuestra que es posible para los países de alto crecimiento, llegando a una tasa de 6 por ciento anual. 
En las predicciones que utilizan regresiones entre países, Chile sigue siendo proyectado como uno de los países de mayor crecimiento en la región; sólo los países muy pequeños y pobres tienen tasas proyectadas que son similares o más altas que la de Chile, por los fuertes efectos de convergencia. En términos de los factores fundamentales que determinan el crecimiento, Chile, como las secciones previas han demostrado, se ubica a la cabeza de la región. Pero se espera que los países del Este de Asia se comporten aún mejor. Según De Gregorio y Lee (2004), una muestra de nueve países del Este de Asia podría crecer 3,8 por ciento anual por habitante entre 2000 y 2010; una de las diferencias más importantes que explican esta brecha es que el Este de Asia es mucho más abierta e integrada al mundo. Un caso alternativo interesante es el de las proyecciones de Consensus Forecast, que simplemente combinan las proyecciones resultantes de cualquier metodología, hechas por analistas profesionales. Su predicción para Chile también es aproximadamente 5 por ciento. Esto en general no es el caso, puesto que por ejemplo las regresiones entre países normalmente predicen mayor crecimiento para los países del Este de Asia que Consensus Forecast. De hecho, Consensus Forecast proyecta que Chile crecerá más rápidamente que muchos países del Este de Asia, incluyendo Corea del Sur, y el crecimiento proyectado para Chile durante los próximos 10 años lo ubica en el primer decil de países.

Crecer en un promedio de 5 por ciento es bastante importante, puesto que con las típicas fluctuaciones del ciclo económico sería bastante probable que Chile tuviese períodos de crecimiento cercano a 7 u 8 por ciento, y desaceleraciones de entre 2 y 3 por ciento. Sin embargo, dado el marco actual de la política macroeconómica de Chile, es probable que estas fluctuaciones sean moderadas. De todas maneras, también hay áreas que se pueden mejorar y donde una mejora traería beneficios en términos de crecimiento y bienestar. Como ya se vio, un aumento en el gasto en ID aumentaría la innovación y la adopción de tecnologías, especialmente si esta actividad se emprende en el sector privado, donde la ausencia de gasto en ID es más evidente. Mejorar la calidad de la educación y asegurar una mayor integración social como una forma de compensar la desigualdad, también estimularía el crecimiento. A su vez, existen algunas áreas institucionales, tales como el cierre de una empresa y la generación de garantías, donde sería posible un progreso sustancial. Finalmente, una política social buena y activa, que reduzca el riesgo de que los esfuerzos por aminorar la desigualdad resulten en políticas que socaven el crecimiento, es muy importante. La clave es combatir la desigualdad sin dañar el crecimiento y el empleo. 


\section{Conclusiones}

\subsection{Acerca de los fundamentos del crecimiento}

He enumerado varias áreas de política donde es posible hacer mejoras que fomentarían el crecimiento en Chile. Es una tentación seguir agregando a lo que ya es una lista larga, pero finalmente la pregunta que se busca responder es: ¿Cuáles son los fundamentos principales que sustentan la acumulación de capital humano y físico y mejoran la productividad, en resumen, los que determinan el crecimiento económico?

En un libro reciente, William Easterly (2001) ofrece una respuesta simple y sin embargo profunda a esta pregunta: "Para progresar desde la pobreza hacia la riqueza, debemos recordar que las personas hacen aquello por lo que se les paga. Ya tenemos evidencia estadística que respalda las teorías de cómo las panaceas han fracasado y cómo las políticas basadas en incentivos pueden funcionar" (p. xii). Y concluye que "Hemos aprendido de una vez que no hay pociones mágicas que pueden lograr un final feliz para nuestra búsqueda del crecimiento. La prosperidad ocurre cuando todos los participantes en el juego del desarrollo cuentan con los incentivos precisos” (p. 289).

A mí me gustaría ir un paso más allá e intentar responder ¿Cuáles son los factores fundamentales que incentivan el crecimiento? ¿Cuáles son los incentivos que llevan a las personas a dedicar sus esfuerzos a la actividad productiva? Dada la experiencia de la economía chilena, y la noción de que es importante lograr los incentivos correctos, creo que dos principios elementales forman la base del crecimiento:

- Garantizar el derecho de propiedad. Cuando la gente invierte en su propio capital humano o cuando los empresarios invierten en plantas y equipos o nuevas técnicas para aumentar su productividad, deben tener la seguridad de que los beneficios de estas inversiones no les serán expropiados. Para esto, los derechos a la propiedad deben ser claramente definidos y respetados.

Una estructura apropiada de premios. La inversión y el esfuerzo deben premiarse adecuadamente. Esto es esencial para fomentar la creatividad, el espíritu emprendedor, y una asignación de talentos favorable al crecimiento.

En términos de la política, garantizar el derecho de propiedad significa establecer reglas del juego claras. 
Es inevitable que algunas políticas o cambios de política tendrán efectos redistributivos. Los cambios en la política tributaria, por ejemplo, alteran la rentabilidad de la inversión en capital físico y humano, de hecho reduciendo o aumentando el valor de ese capital. Mejorar la regulación también a menudo cambia la rentabilidad. Una empresa que se ha convertido en un monopolio puede encontrarse obligada a dar pasos para reducir su poder monopólico, que reduce sus ganancias. En resumen, la redistribución ocurre. Lo importante es tener claro los límites del derecho de propiedad. Para lograr esto, las naciones deben contar con instituciones sólidas y reglas claras que definen y delimiten el derecho a la propiedad, además de mecanismos que aseguren una justa compensación cuando los cambios de política generan efectos redistributivos.

En una democracia, los impuestos generalmente se aprueban en el poder legislativo, y nadie debe sorprenderse, aunque a algunos quizás no les guste, cuando ocurren cambios. Por supuesto, una Constitución sólida y buenas leyes protegerán de arbitrariedades legales, como por ejemplo en el plano tributario, y la expropiación directa. La lección aquí, nuevamente, trata de la necesidad de contar con instituciones fuertes, y estas instituciones deben tener una clara orientación favorable a la protección del derecho de propiedad.

Como hemos visto en este trabajo, Chile ya contaba con instituciones fuertes mucho antes del despegue de mediados de los 80. Pero, incluso cuando las instituciones de un país se orientan a proteger los derechos de propiedad y a generar incentivos para el crecimiento de la productividad y la inversión, eso no es suficiente. Un ambiente macroeconómico estable también forma parte importante de la garantía al derecho de propiedad. Una inflación alta e inestable también redistribuye el ingreso, normalmente desde los que ahorran hacia los que piden prestado, y esto desincentiva el ahorro. En efecto, al liquidar la deuda pública nominal, la inflación también redistribuye la riqueza desde los tenedores de bonos hacia los gobiernos. Se puede decir lo mismo de congelamientos de depósitos cuando ocurren crisis bancarias y otras situaciones parecidas. La estabilidad macroeconómica por lo tanto promueve el crecimiento al crear un ambiente seguro para la inversión, que permite a los emprendedores concentrar su esfuerzo en los riesgos usuales e inevitables del negocio.

Pero el segundo principio, una estructura de estímulos adecuada, también es importante. Se puede concebir un país donde los derechos de propiedad estén seguros e inmutables pero el sector corporativo consiste en un grupo de monopolistas que gozan de significativas barreras a la en- 
trada. Entonces, nadie tendrá incentivos para invertir o entrar a competir: los monopolistas no necesitarán hacerlo y cualquier inversor potencial se enfrentará con una gran desventaja. Entonces, la forma de establecer este segundo principio en el terreno económico es la competencia, plena y fuerte, que permite a los mercados operar eficientemente ${ }^{38}$. La apertura y el libre comercio, mientras tanto, son esenciales para asegurar y aumentar la competencia, especialmente en una economía pequeña. Para competir con éxito, las empresas deben ser eficientes y creativas. En ausencia de una potencial competencia, cualquier empresa establecida no tendrá incentivos para ser eficiente.

Por supuesto habrá externalidades que requieren de una intervención pública; por ejemplo y recordando el tema discutido anteriormente, la incapacidad de los innovadores de aprovechar plenamente los beneficios de su innovación significa que la ID tenderá a ser escasa. Fomentar la ID a través de políticas públicas es, por lo tanto, una buena idea. Pero siempre se debe recordar el principio de Easterly. Si el apoyo para la ID genera captura de rentas y permite que proyectos dudosos se beneficien del apoyo gubernamental, una buena política en principio puede arrojar malos resultados en la práctica. Las políticas deben diseñarse teniendo en cuenta los incentivos que crean. Consideraciones similares son a la vez válidas para la inversión pública.

El segundo principio también tiene implicancias para la política social. Es importante que los trabajadores, y no solo las empresas, reciban beneficios acordes con sus esfuerzos. Una aspiración natural de los padres, especialmente entre los pobres, es que sus hijos tengan una vida más próspera que la de ellos. Para esto necesitan oportunidades. El ingreso que un individuo recibe del trabajo dependerá de la productividad de su labor y por lo tanto el objetivo de la política educativa debe ser el de transferir el conocimiento útil y así transformar a las personas en trabajadores más productivos. Dicho de forma más general, el segundo principio se traduce en la movilidad social, o la igualdad de oportunidades, en el frente social.

Podemos entender mejor las fortalezas y los desafíos de Chile a la luz de estos dos principios. Las instituciones chilenas son fuertes, su ambiente macroeconómico es estable, y por lo tanto los derechos de propiedad están bien protegidos. Adicionalmente, la economía chilena es muy abierta, la competencia es fuerte, las políticas sociales están bien diseñadas y el sector financiero asigna eficientemente los fondos a buenos proyectos e inversionistas con buenas ideas. Por lo tanto, existen buenos incentivos para la

38 Parente y Prescott (2000) han demostrado la importancia de la competencia $\mathrm{y}$ que los mercados funcionen bien formalmente. 
inversión, que puede esperar una compensación adecuada. La calidad de la educación debe mejorarse y deben reforzarse los esfuerzos por reducir la desigualdad a través de políticas sociales para mejorar las condiciones de vida de los pobres y la crear condiciones favorables a una mayor movilidad social. Un aumento en los incentivos de la innovación y la adaptación del progreso tecnológico también aumentará las posibilidades de lograr un crecimiento rápido y sostenido. Desde el punto de vista de las actividades de gobierno, es importante preocuparse de cómo fomentar el crecimiento y ayudar a los pobres y los menos aventajados, al mismo tiempo que se minimizan las distorsiones de política. Esto no es un desafío menor, pero siempre que se mantenga el crecimiento, es más fácil, puesto que se pueden reducir las tentaciones del populismo pero nunca eliminarlos.

Finalmente, aunque la política pública puede lograr mucho en términos de crear un ambiente pro-crecimiento, ni siquiera eso es suficiente. Algo de buena suerte ayuda. La suerte puede asumir la forma de una dotación abundante de recursos, un clima favorable, vecinos prósperos y cooperadores, un ambiente internacional fuerte, y otros. Desafortunadamente, un país puede hacer poco para mejorar su suerte, pero sí puede prepararse para explotar plenamente cualquier golpe de suerte que aparezca.

\subsection{Competencia, privatización, regulación e innovación}

He argumentado que para lograr un crecimiento de la productividad, incentivar la innovación y asignar el talento a las actividades productivas, los esfuerzos y la creatividad de las personas deben recibir los beneficios correspondientes. $\mathrm{Y}$ en ese sentido la competencia es esencial. La apertura de la economía conlleva la competencia. Aquellos que quieran jugar en los mercados globales y defenderse de la competencia extranjera deben ser eficientes y productivos. Sin competencia, la regulación debe diseñarse para enfrentar la competencia.

En este sentido, Chile ha progresado en años recientes, un buen ejemplo es la creación del Tribunal de Libre Competencia independiente. Como un Banco Central independiente, un Tribunal de Libre Competencia independiente y especializado puede minimizar los conflictos de interés y garantizar la competencia. En otra área más estrecha pero de la misma índole, en el futuro, las disputas entre empresas eléctricas chilenas serán resueltas por un panel independiente, en lugar del Ministro de Economía. De hecho, normalmente se necesitan muchas reformas reglamentarias, especial- 
mente dados los rápidos avances tecnológicos en este sector. Pero desde mi punto de vista, la base institucional más importante debe definir cómo se resuelven las disputas, quién es responsable de establecer los reglamentos, y quién se encarga de administrarlas. Otorgar la independencia y exigir rendición de cuentas (accountability) de los reguladores y definir paneles independientes para resolver conflictos envía una señal fuerte a los inversionistas sobre la estabilidad de las reglas del juego.

La privatización ha jugado un papel importante en la profundización de los mercados chilenos. Ha sido particularmente importante en el caso de los servicios públicos. Éste es el típico caso donde la evidencia entre países no ha podido estimar los efectos en el crecimiento, pero sin duda algo ha habido, y a veces ganancias significativas. La privatización ha fomentado la inversión y ha sido un vehículo importante para atraer la inversión extranjera directa, que sabemos tiene impactos positivos en el crecimiento. Mantener al gobierno fuera de la actividad productiva, pero involucrado en su regulación, fomenta la competencia e incentiva la inversión y el crecimiento de la productividad. Un ente que produce y regula, el Estado en el caso de las empresas públicas, enfrenta enormes conflictos de interés. Un caso importante es la lucha continua de los ministros de hacienda para evitar que las empresas públicas se conviertan en fuentes de desequilibrio fiscal, mientras que esas empresas terminan por sacrificar proyectos de inversión rentables. Adicionalmente, los incentivos de sus gerentes no necesariamente serán compatibles con la innovación y la eficiencia. En efecto, el gobierno corporativo de las empresas que aún continúan siendo públicas, aquellas donde hay motivos especiales para no privatizarse, deben acercarse a las mejores prácticas de las empresas privadas. Esto induce a la eficiencia y reduce la interferencia política, que a menudo se disfraza de promotora del bienestar social u otras causas "buenas". Se ha logrado mucho, pero quedan áreas para mejorar.

No tenemos buenas estimaciones del aporte al crecimiento económico de cambios regulatorios y otras reformas microeconómicas. Pero ello no debería paralizar la búsqueda de nuevas reformas, puesto que aunque su medición puede ser elusiva, los beneficios sin duda son grandes. Como he destacado aquí, las instituciones que mejoren los mercados son esenciales para el crecimiento. Incluso si algunas no contribuyen directamente a un crecimiento más rápido, mejorar la competencia definitivamente brinda ganancias de bienestar. 


\section{REFERENCIAS}

Acemoglu, D., S. Johnson y J. Robinson: "Institutions as the Fundamental Cause of Long-Run Growth”. Por aparecer, Handbook of Economic Growth, 2004.

Álvarez, R., G. Crespi y J. Ramos: "The Impact of Licenses on a 'Late Starter' LDC: Chile in the 1990s”. World Development, Vol. 30, No 8, pp. 1445-1460, 2002.

Aschauer, D.: “Is Public Expenditure Productive?”. Journal of Monetary Economics, 23, pp. 177-200, 1989.

Aten, B., A. Heston y R. Summers: "Penn World Tables Version 6.1". Center for International Comparisons at the University of Pennsylvania (CICUP), 2002.

Banco Mundial: Doing Business 2005. Understanding Regulation. Banco Mundial, IFC y Oxford University Press, 2004.

Barro, R.: "Determinants of Economic Growth A Cross-Country Empirical Study". NBER Working Paper $\mathrm{N}^{\circ}$ 5698, 1997.

Barro, R.: "Determinants of Economic Growth: Implications of the Global Evidence for Chile”. Cuadernos de Economía, Año 36, Vol. 107, pp. 443-478, 1999.

Barro R. y X. Sala-i-Martin: Economic Growth. McGraw-Hill, 1995.

Barro R. y X. Sala-i-Martin: Economic Growth. Cambridge MA: MIT Press, 2004, $2^{\text {a }}$ edición.

Beyer, H. y R. Vergara: "Productivity and Economic Growth: The Case of Chile". En N. Loayza y R. Soto (eds.), Economic Growth: Sources, Trends and Cycles. Banco Central de Chile, 2002.

Bergoeing, R., P. Kehoe, T. Kehoe y R. Soto: "Decades Lost and Found: Mexico and Chile Since 1980”. Review of Economic Dynamics, 5(1), pp. 166-205, 2002.

Bosworth, B. y S. Collins: "The Empirics of Growth: An Update”. World Bank paper, 2003.

Bravo-Ortega, C. y J. De Gregorio: "The Relative Richness of the Poor. Natural Resources, Human Capital and Economic Growth”. Working Paper $\mathrm{N}^{\circ} 139$, Central Bank of Chile, 2002.

Bustos, A., E. Engel, y A. Galetovic: "Could Higher Taxes Increase the Long-Run Demand for Capital? Theory and Evidence for Chile”. Journal of Development Economics, 73, pp. 675-697, 2003.

Calderón, C. y A. Chong: “Are Labor Market Regulations and Obstacle for Growth?”. Mimeo. Banco Central de Chile, 2003.

Calderón, C. y L. Servén: "The Effects of Infrastructure Development on Growth and Income Distribution”. Banco Central de Chile, Documento de Trabajo No 269, 2004a.

Calderón, C. y L. Servén: “Trends in Infrastructure in Latin America, 1980-2001”. Banco Central de Chile, Documento de Trabajo $N^{\circ} 269$, 2004b.

Chumacero, R., R. Fuentes, y K. Schmidt-Hebbel: “Chile's Free Trade Agreements: How Big is The Deal?” Banco Central de Chile, Documento de Trabajo $N^{\circ} 264$, 2003.

Coeymans, J.E.: "Ciclos y Crecimiento Sostenible a Mediano Plazo en la Economía Chilena”. Cuadernos de Economía No 107, pp. 546-596, 1999.

Coeymans, J.E. y F. Larraín: "Efectos de un Acuerdo De Libre Comercio entre Chile y Estados Unidos: Un Enfoque de Equilibrio General”. Cuadernos de Economía Año 31, No 94, pp. 357-399, 1994. 
Consensus Forecast 2003-2013: “Global Outlook 2003-2013”. Consensus Economics Inc., 2003.

Corbo, V. y S. Fischer: "Lessons from the Chilean Stabilization and Recovery". En B. Bosworth, R. Dornbusch y R. Laban (eds.), The Chilean Economy. Policy Lessons and Challenges. Brookings, 1994.

Cowan, K., A. Micco y C. Pages: "Labor Adjustment in Chile". Por aparecer, Economía, 2003.

De Gregorio, J.: "Economic Growth in Latin America”. Journal of Development Economics, $\mathrm{N}^{\circ}$ 39, pp. 59-84, 1992.

De Gregorio, J.: "Inflation, Growth and Central Banks: Theory and Evidence”. Banco Mundial, Policy Research Working Paper No 1575, 1996.

De Gregorio, J.: "Productivity Growth and Disinflation in Chile”. NBER Working Paper No 10360, 2004.

De Gregorio, J. y J. W. Lee: "Economic Growth in Latin America: Source and Prospects”. Documentos de Trabajo, Serie Economía, CEA N 66, 1999.

De Gregorio, J. y J. W. Lee: "Growth and Adjustment in East and Latin America". Por aparecer en Economía.

De la Cuadra: "El Crecimiento del Producto Potencial en los Últimos Años”. Mimeo, Forecast, 2002.

Díaz, L., R. Lüders, y G. Wagner: "La República en Cifras”. Mimeo. Universidad Católica, 2004.

Djankov, S., La Porta, R., F. López-De Silanes, y A. Shleifer: “The Regulation of Entry”. The Quarterly Journal of Economics, Vol. 117, pp. 1-37, 2002.

Dollar, D. y A. Kraay: "Institutions, Trade and Growth". Journal of Monetary Economics, $\mathrm{N}^{\circ} 50$ (1), pp. 133-162, 2002.

Easterly, W.: The Elusive Quest for Growth. Economist's Adventures and Misadventures in the Topics. MIT Press, 2001.

Edwards, S.: "Openness, Productivity and Growth: What Do We Really Know". The Economic Journal, Vol. 108, No 447, pp. 680-702, 1997.

Fischer, S.: "The Role of Macroeconomics Factors in Growth". Journal of Monetary Economics, Vol. 32, pp. 485-512, 1993.

Fondo Monetario Internacional: World Economic Outlook and Policy Issues. FMI, 2004.

Fuentes, R., M. Larraín y K. Schmidt-Hebbel: "Fuentes del Crecimiento y Comportamiento de la Productividad Total de Factores en Chile”. Mimeo. Banco Central de Chile, 2004.

Fuentes, R. y C. Maquieira: "Why People Pay: Understanding High Performance in Chile’s Financial Market”. En M. Pagano (ed.), Defusing Default: Incentives and Institutions. Banco Interamericano para el Desarrollo, Washington D.C., 2001.

Gallego, F. y C. Johnson: "Teorías y Métodos de Medición del Producto de Tendencia: Una Aplicación al Caso de Chile”. Revista de Economía Chilena, Vol. 4, N² 2, pp. 27-58, 2001.

Gallego F. y N. Loayza: “La Época Dorada del Crecimiento en Chile: Un Problema Financiero”. Revista de Economía Chilena, Vol. 5, № 1, pp. 37-63, 2002.

Gavin, M. and R. Perotti: "Fiscal Policy in Latin America". NBER Macroeconomics Annual 1997, pp. 11-60, 1997. 
Glaeser, E., R. La Porta, F. López-de-Silanes y A. Shleifer: "Do Institutions Cause Growth?”. NBER Working Paper No 10568, 2004.

Gollin, D.: “Getting Income Shares Right”. Journal of Political Economy, Vol. 110(3), pp. 458-474, 2002.

Hall, R. y C. Jones: "Why Do Some Countries Produce So Much More Output Per Worker Than Others?”. The Quarterly Journal of Economics, 114(1), pp. 83116, 1999.

Hviding: "Potential Output Growth in Chile During 1986-2000, and in the Future, in Chile, Selected Issues”. Country Report 01/120, Fondo Monetario Internacional, 2001.

Kaufmann, D. y A. Kraay: “Growth without Governance”. Economía Vol. 3, № 1, pp. 169-229, 2002.

Klenow, P. y A. Rodríguez-Clare: "The Neoclassical Revival in Growth Economics: Has it Gone Too Far?”. NBER Macroeconomics Annual 1997, 1997.

Lederman, D. y W. Maloney: "I\&D and Development”. Mimeo. Banco Mundial, Washington, DC., 2003.

Lederman, D. y L. Sáenz: "Innovation around the World: A Cross-Country Data Base of Innovation Indicators”. Mimeo. Banco Mundial, Washington, DC., 2003.

Levine: "Finance and Growth: Theory and Evidence". Por aparecer en Handbook of Economic Growth, 2004.

Loayza, N., P. Fajnzylber, y C. Calderón: "Economic Growth in Latin America and the Caribbean. Stylized Facts, Explanations, and Forecasts”. Mimeo. Banco Mundial, 2002.

Maddison, A.: Monitoring the World Economy 1820-1992. París: OCDE, 1995.

Ministerio de Hacienda: Estado de la Hacienda Pública 2004. Ministerio de Hacienda, Chile, 2004.

OCDE: “Science, Technology and Industry Scoreboard 2003”. París: OCDE, 2003.

Parente, S. y E. Prescott: Barriers to Riches. MIT Press, 2002.

Rodríguez, F. y D, Rodrik: “Trade Policies and Economics Growth: a Skeptics' Guide to the Cross-National Evidence”. NBER Macroeconomics Annual 2000, pp. 261325, 2001.

Sachs, J.: "Institutions Don't Rule: Direct Effects of Geography on Per capita Income”. NBER Working Papers N $\mathrm{N}^{\circ}$ 9490, 2003.

Sachs, J. y A. Warner: "Economic Reform and the Process of Global Integration". Brookings Papers on Economic Activity, No 1, pp. 1-118, 1995.

Sanhueza, G.: "La Crisis Financiera de los Años Ochenta en Chile: Análisis de sus Soluciones y sus Costos”. Economía Chilena, Vol. 2, No 1, 1999.

Solow, R.: "Technical Change and the Aggregate Production Function". Review of Economics and Statistics, $\mathrm{N}^{\circ}$ 39, pp. 312-320, 1957.

Tokman, A.: "Educación y Crecimiento". Mimeo. Banco Central de Chile, 2004.

Valenzuela, A.: “Comments”. En B. Bosworth, R. Dornbusch y R. Laban (eds.), The Chilean Economy. Policy Lessons and Challenges. Brookings, 1994.

Velasco, A.: “The State and Economic Policy: Chile 1952-1992”. En B. Bosworth, R. Dornbusch y R. Laban (eds.), The Chilean Economy: Policy Lessons and Challenges. Brookings, 1994.

Vergara, R.: “Taxation and Private Investment: Evidence for Chile”. Mimeo. Universidad Católica de Chile, 2004. 
Villafuerte, M.: “Export Specialization and Economic Growth”. En FMI Occasional Paper 231, pp. 71-85, 2004.

Wacziarg, R. y K. Welch: “Trade Liberalization and Growth: New Evidence”. Mimeo, Stanford University, 2003.

Winters, A., N. McCulloch, y A. McKay: "Trade Liberalization and Poverty: The Evidence So Far”. Journal of Economic Literature, 42(1): 72-115, 2004.

Young, A.: "The Tyranny of Numbers: Confronting the Statistical Realities of the East Asia Growth Experience”. Quarterly Journal of Economics, 110, pp. 641-680, 1995. 